\title{
Behavior of Weld to S960MC High Strength Steel from Joining Process at Micro-Jet Cooling with Critical Parameters under Static and Fatigue Loading
}

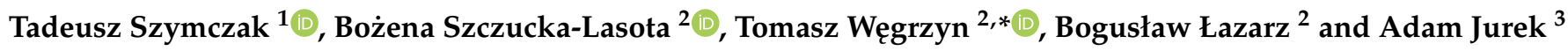 \\ 1 Department of Vehicle Type-Approval \& Testing, Motor Transport Institute, Jagiellońska 80, \\ 03-301 Warszawa, Poland; tadeusz.szymczak@its.waw.pl \\ 2 Faculty of Transport and Aviation Engineering, Silesian University of Technology, 40-119 Katowice, Poland; \\ bozena.szczucka-lasota@polsl.pl (B.S.-L.); boguslaw.lazarz@polsl.pl (B.Ł.) \\ 3 Novar Sp. z o. o., Towarowa 2, 44-100 Gliwice, Poland; adam.jurek@novar.pl \\ * Correspondence: tomasz.wegrzyn@polsl.pl; Tel.: +48-32-603-4389
}

check for

updates

Citation: Szymczak, T;;

Szczucka-Lasota, B.; Wẹgrzyn, T.;

Łazarz, B.; Jurek, A. Behavior of Weld

to S960MC High Strength Steel from

Joining Process at Micro-Jet Cooling with Critical Parameters under Static and Fatigue Loading. Materials 2021, 14, 2707. https://doi.org/10.3390/ ma14112707

Academic Editor: Bolv Xiao

Received: 16 April 2021

Accepted: 18 May 2021

Published: 21 May 2021

Publisher's Note: MDPI stays neutral with regard to jurisdictional claims in published maps and institutional affiliations.

Copyright: (c) 2021 by the authors. Licensee MDPI, Basel, Switzerland. This article is an open access article distributed under the terms and conditions of the Creative Commons Attribution (CC BY) license (https:// creativecommons.org/licenses/by/ $4.0 /)$.

\begin{abstract}
The paper is focused on testing the weld of the S960MC steel produced at the micro-jet cooling under static and fatigue loading at critical parameters. This kind of material was in the form of a sheet with a thickness equal to $2 \mathrm{~mm}$. The joint was obtained using three different types of welding wires: EDFK 1000, Union NiMoCr and Union X96 at the same parameters of the process. The joints were examined using non-destructive and destructive tests. The results from non-destructive experiments enable us to assess the quality of the welds directly before the joining process. In contrast, the destructive one allows following welds behavior under different loading conditions with their critical parameters. The bending experiments confirmed the good plastic properties of the weld, expressed by no cracks in the region tested in many variants of the joint manufactured. The results from static tests indicated a significant reduction of mechanical parameters of the weld in comparison to the base metal, expressed by 50\% differences. Fatigue data have enabled us to follow the welding behavior at the increasing amplitude of axial stress up to fracture at constant amplitude value covering the following values of stress $650 \mathrm{MPa}-100 \mathrm{MPa}$. Variations of total energy are presented at different values of several cycles up to fracture. Fracture regions are collected for analysis of the joint region features under cyclic loading. They have indicated differences in weld cracking depended on the stress level. Finally, the Wöhler S-N curve of the weld was determined, indicating the value of the fatigue limit of the weld tested, i.e., $100 \mathrm{MPa}$. The weld at the Union NiMoCr welding wire was indicated as the joint having the highest resistance on static and fatigue loadings.
\end{abstract}

Keywords: high-strength steel; components; joining; transport; micro-jet; welding; mechanical resistance; parameters; microstructure; mini-specimen; fracture; fatigue limit

\section{Introduction}

High-Strength Steels (HSS) belong to modern metals used in a lot of branches of the industry concerning their mechanical properties, such as ultimate tensile strength and yield stress, which are higher compared to typical structural materials [1,2]. Among them, the following material types can be indicated: Strenx [1,3], Docol [4,5], Amstrong Ultra [6] and Optim QC [7]. Their application is very wide, and it is selected based on comparing the value of stress due to operational conditions and mechanical parameters at microstructure features [1,2]. Therefore, they are employed for manufacturing different components called: car bodies, stringers [8], frames [9], bumper reinforcement and door beams [5], Rear Underrun Protective Device [1,10], booms [6,7], platform [8], tippers and aerial platforms [6].

Until now, unalloyed steel with a minimum yield strength of $355 \mathrm{MPa}$ and minimum impact strength $\mathrm{KV}-20=27 \mathrm{~J}$ was used for the construction of the container part 
of the container-type vehicle [11]. Due to low strength, the walls of the containers were massive, with a thickness of up to $5 \mathrm{~mm}$. Recently, attempts have been made to use highstrength steel (e.g., S960 grades) for the construction of containers, which has a strength of 2.5 times greater, which makes it possible to significantly reduce the thickness of the container wall, and thus the entire weight of the container [12]. This is very important in transport, as reducing the weight of the container will allow you to carry more loads. It is a very economical solution [13]. Worth noticing, the production process for elements made of HSS materials is very different, and it can be conducted using welding, screwing, or bolting techniques. Moreover, in the case of the last connection methods, the sub-components used for the joining have certificates, while the quality of the first one depends on the qualifications of the welding group. This problem is considered by a lot of research teams $[9,14]$, which examined parameters of the joining technique or modified ones applying additional sub-elements such as micro-jet cooling device $[15,16]$ or hybrid welding process $[17,18]$. These efforts are transferred for various kinds of high-strength steel focusing on the S960MC $[15,17,18]$, which is an attractive kind of metal because it is produced in a lot of forms such as sheets, tubes and plates $[1,6]$. The Strenx 960MC is very good weldable, cold-formed and machined by cutting. Therefore, typical applications are represented by advanced lifting devices such as mobile cranes and lighter transport solutions and components $[3,6]$. They indicate the steel and their joints can be subjected to various types of loading, including: static and cyclic, which influence mechanical parameters important for engineering practice and inspection stages for a correct designing and service life, respectively. Therefore, different tests are used for determining the steel reaction [19]. They follow the behavior of the welded zones with different filler materials up to fatigue limits indicating its value close to $100 \mathrm{MPa}$ at a very narrow stress range represented by the following values 100-300 MPa, [18]. Moreover, taking these data, differences between the role of metal used for filling can be easily indicated. Besides fatigue tests, hardness experiments are still used as the fundamental probe for assessing the quality of a welded joint made of the S960MC steel [18]. This method is very helpful at the calibration of the welding process as well as the hybrid joining technique. Moreover, the technique is very typical; nevertheless, some differences between welded regions can be easily indicated [18]. This type of results enables to follow concludes on the quality of joint if sufficient numbers of measurement regions are collected [20]. This approach can also be evidence in $[17,21]$, which presents data from micro-hardness tests [17] on the joint manufactured at the Gas Metal Arc Weld (GMAW). The same sentence, as it has been formulated in the case of the hardness probe, can be addressed to impact test, which has enabled indicating advantages of the laser and laser welding process, expressed by the following values of accumulated energy reaching $57 \mathrm{~J}$ and $49 \mathrm{~J}$, respectively. The same kind of test was also used for differencing features of the S960MC welds produced by various types of the process [22]. In this case, the experiment type was very effective and has enabled us to distinguish variations of impact toughness. Some authors [23] have used a combined approach such as fracture toughness results to predict fatigue endurance of a weld of the S960MC. They have presented a fatigue curve at stress value close to data shown in [18], indicating good agreement between the method and experimental efforts.

Welding S690 steel grades is not easy. For making joints with a thickness of about $6 \mathrm{~mm}$, it is absolutely necessary to use preheating and control the inter-stitch temperature. Joints made of these steels have low fatigue strength and low relative elongation. The softening of the HAZ (Heat Affected Zone) is one of the major issues of HSS welding [24,25]. There is no information in the technical literature on the fatigue strength of welded joints made of S960 steel grade. Thin-walled joints are a major welding problem, as they can be prone to welding cracks.

Pipe joints made of HSS steel with variable wall thickness were tested. It has been shown that a thick-walled joint has better fatigue properties than a thin-walled joint due to the reduction of the stress concentration factor. In fact, the presence of fatigue cracks or otherwise induced defects in such connections poses a potential safety risk to the structure. 
The authors found the possibility of cold cracks, especially in joints of greater thickness, where they recommend using preheating. It is also related to the higher hydrogen content in the joint obtained without preheating $[26,27]$.

In welding AHSS (Advanced High Strength Steel) steels, there is a need to modify the technology to improve the strength and plastic properties of the joint. This is due to the slightly different metallographic structure of the weld and the base material (expanded ferrite and martensite in the weld). For this purpose, for the first time, it was decided to test the micro-jet cooling method during S960MC welding (research gap), which can lead to the fragmentation of the joint structure, which is related to the improvement of the mechanical properties of the joint. For the first time, fatigue tests of such a joint were performed, which are the most important information leading to the verification and validation of the new design and technology.

The aim of the article was to develop a material and technological solution enabling the production of a thin-walled structure made of difficult-to-weld steel, characterized by the best mechanical properties. Therefore, in the article, it was decided to very carefully check the possibility of MAG (Metal Active Gas) welding S960MC steel using various parameters, materials and welding methods. It was also decided to check the possibility of welding S960MC steel to obtain the best mechanical properties. It was decided to test three electrode wires with a variable content of carbon and other alloying elements, and it was decided to test the use of two different shielding mixtures in the MAG welding process. Independently, it was decided to check the possibility of making a thin-walled structure of the S960MC steel joint with the use of micro-jet cooling, believing that this type of cooling would allow for the fragmentation of the dominant martensitic and ferritic structures. It was decided to perform numerous non-destructive and destructive tests to determine the most favorable welding and cooling parameters of the micro-jet, which allows the best mechanical properties of the joint to be obtained. Taking into account the results discussed above, the two research paths for examining the S960MC weld are evidenced. The first one is represented by typical experiments such as hardness and fatigue tests but at a narrow range of experimental procedures, while the second manner is expressed by complex approach, i.e., theoretic-experimental. From the practical and scientific point of view, these manners are suited for selected loading regimes, without details on the energetic aspects of the fatigue process as well as cases at high value of stress, including an increase of amplitude related to the fractured moment. The most important point of the research was to check the fatigue strength after welding S960MC steel. For this purpose, the size of the samples was specially designed, and fatigue strength tests were performed on very sensitive equipment.

In addition to the use of micro-jet cooling, the type of shielding gas plays an important role. Only the use of the $\mathrm{Ar}-\mathrm{CO}_{2}$ mixture allows obtaining the correct joints. Further research focused on the evaluation of joints made with three different welding wires. M21 (Ar-18\% $\mathrm{CO}_{2}$ ) cover and micro-jet cooling were always used. Tensile and fatigue tests were performed. The influence of the selection of the electrode wire on the mechanical properties of the joint was analyzed. The wires had a comparable chemical composition but differed slightly in carbon content. It was believed that the carbon content of the wire could affect the mechanical properties of the joint: both tensile strength and fatigue strength.

\section{Materials and Methods}

\subsection{Specimen for Welding and Parameters of the Joining Process}

Welded butt joints of S960MC steel with a thickness of $2 \mathrm{~mm}$, length $200 \mathrm{~mm}$ and width $300 \mathrm{~mm}$ were made. The MAG (Metal Active Gas) welding process was used according to the standard requirements (EN 15614-1). The preparation of the material for single-stitch welding is shown in Figure 1. 


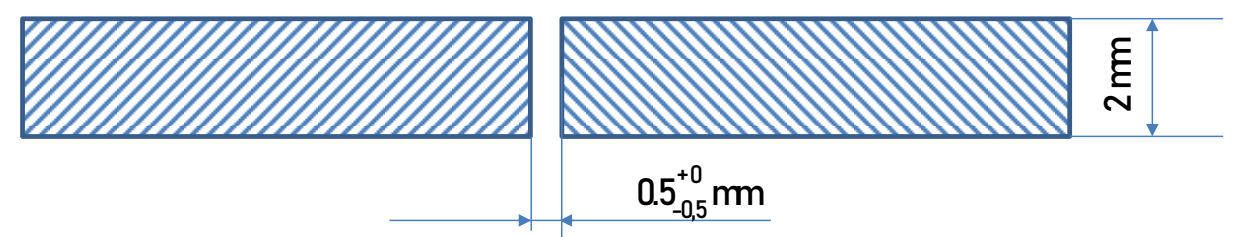

Figure 1. Preparation of the element for metal active gas (MAG) welding with micro-jet cooling.

It was decided to make test joints using two shielding gases: $\mathrm{CO}_{2}$ and gas mixture M21, i.e., $\mathrm{Ar}+18 \% \mathrm{CO}_{2}$ (according to the PN-EN 14175 standard). All of the sheet metal samples were welded with three different electrode wires (ED-FK 1000, Union NiMoCr and UNION X96) with a similar chemical composition but with a slightly increasing carbon content in each of them $(0.08 \% \mathrm{C} ; 0.09 \% \mathrm{C} ; 0.11 \% \mathrm{C})$ :

- EN ISO 12534-A G 695 M Mn4Ni1.5Cr-Union (Voestalpine Böhler Welding, Hamm, Germany) NiMoCr (C 0.08, Si 0.6, Mn 1.7, Cr 0.2, Mo 0.5 and Ni 1.5);

- $\quad$ EN ISO 16834-A G 896 M21 Mn4Ni2CrMo-ED-FK 1000 (FLIESS, Duisburg, Germany) (C 0.09, Si 0.8, Mn 1.8, Cr 0.31, Mo 0.55 and Ni 2.2);

- EN ISO 16834-A G 895 M21 Mn4Ni2.5CrMo-UNION X96 (Voestalpine Böhler Welding, Hamm, Germany) (C 0.11, Si 0.78, Mn 1.9, P 0.01, S 0.009, Cr 0.35, Mo 0.57, Ni 2.23, $\mathrm{V}$ 0.004, $\mathrm{Cu}$ 0.02, Ti 0.057, Zr 0.001 and $\mathrm{Al}$ 0.002).

The chemical composition of the three selected electrode wires was comparable. A slight difference in the carbon amount was noted. The carbon content influences the steel weldability and tensile strength. There were also slight differences in the chemical composition between the base material and the electrode wires. Molybdenum and nickel, which are not present in steel, were additionally introduced in the electrode wires. This is conducted in order to increase the plastic properties of the joint. Vanadium and copper in both the base material and the filler wires are low. However, there are noticeable differences in the content of aluminum, especially titanium, which is responsible for the precipitation strengthening of the joint [28].

In the initial stage, the MAG welding parameters were established: current 95-105 A, arc voltage (17-22 V) and welding speed ( $250-350 \mathrm{~mm} / \mathrm{min})$. Observations were made $48 \mathrm{~h}$ after welding to ensure that no cold cracks would form (by the recommendations of the standard PN-EN 1090-2). Welding tests were performed with the assumed gas flow of $14 \mathrm{~L} / \mathrm{min}$. The input energy during the welding of thicker sheets was below the recommended value of $4 \mathrm{~kJ} / \mathrm{mm}$. All welding tests were carried out without preheating. The best results (correct joint form) were put in Table 1.

Table 1. The welding current of S960MC steel.

\begin{tabular}{ccccc}
\hline $\begin{array}{c}\text { Diameter of the } \\
\text { Electrode, mm }\end{array}$ & $\begin{array}{c}\text { Current } \\
\text { Intensity, A }\end{array}$ & Voltage, V & $\begin{array}{c}\text { Polarization }+ \\
\text { or }-\end{array}$ & $\begin{array}{c}\text { Welding Speed, } \\
\mathbf{m m} / \mathbf{m i n}\end{array}$ \\
\hline 1.0 & 101 & 19 & $\mathrm{DC}^{\text {" }+" ~}$ & 300 \\
\hline
\end{tabular}

The chemical composition and mechanical properties of the S960MC steel are presented in [3]. The gap between sheets was varied in the range $0-1 \mathrm{~mm}$. The correct results were obtained for the gap equal to $0.5 \mathrm{~mm}$, Figure 1 . This case was only taken for further investigation. The most important other parameters of the welding process are given in Table 1.

S960MC steel was welded using micro-jet cooling. Micro-jet cooling parameters were varied in the following way:

- micro-jet gas: argon;

- stream diameter: 60 and $70 \mu \mathrm{m}$;

- gas pressure: 0.6 and $0.7 \mathrm{MPa}$. 
Non-destructive and destructive tests were used to assess the quality of the welds according to the research plan presented in Table 2.

Table 2. The characteristic of the carried tests.

\begin{tabular}{|c|c|c|}
\hline No & Test & Characteristic of Test \\
\hline $\mathbf{I}$ & & Non-Destructive Tests: \\
\hline 1. & Visual testing (VT) & $\begin{array}{l}\text { - was performed with an eye armed with a loupe (Levenhook, Tampa, FL, USA) at } 3 \times \text { magnification and } \\
\text { the test was made using standard auxiliary measures, luxmeter with white light } 520 \text { Lx; } \\
\sqrt{ } \quad \text { tests were carried out in accordance with the requirements of the PN-EN ISO } 17638 \text { standard, } \\
\sqrt{ } \quad \text { evaluation criteria according to the EN ISO } 5817 \text { standard. }\end{array}$ \\
\hline 2. & Magnetic-particle test & $\begin{array}{l}\text { - } \quad \text { was made using the wet method with the following conditions: field strength } 3 \mathrm{kA} / \mathrm{m} \text {, white light } \\
515 \mathrm{Lx} \text {, temperature } 20^{\circ} \mathrm{C} \text {, MR-76 detection means, MR-72 contrast; the device for testing was a } \\
\text { magnetic flaw detector of REM-230 type (ATG, Prague, Czech Republic); } \\
\sqrt{ } \quad \text { the tests were carried out in accordance with the PN-EN ISO } 17638 \text { standard, } \\
\sqrt{ } \quad \text { the evaluation of the tests was carried out in accordance with the EN ISO } 5817 \text { standard. }\end{array}$ \\
\hline II & & Destructive Tests: \\
\hline 3. & The bending test (BT) & $\begin{array}{l}\text { - was carried out using the ZD-40 testing machine (WPM, Leipzig, Germany); } \\
\sqrt{ } \quad \text { tests was carried out in accordance with the PN-EN ISO } 5173 \text { standard, using the ZD- } 40 \text { testing } \\
\text { machine (WPM, Leipzig, Germany), (The tests used: specimens with a thickness of a }=2 \mathrm{~mm} \text {, width } \\
\mathrm{b}=20 \mathrm{~mm} \text {, mandrel } \mathrm{d}=22 \mathrm{~mm} \text {, spacing of supports } \mathrm{d}+3 \mathrm{a}=31 \mathrm{~mm} \text {, and the required angle of } \\
\text { bending } 180 \text {. Five bending test measurements were carried out for each tested joint thickness on the } \\
\text { root side and on the face side). }\end{array}$ \\
\hline 4. & $\begin{array}{l}\text { Examination of } \\
\text { microstructure }\end{array}$ & $\begin{array}{l}\text { - } \quad \text { was made using the of specimens etched with Adler reagent using light microscopy (Neophot 32, Carl } \\
\text { Zeiss Jena, Jena, Germany); } \\
\sqrt{ } \quad \text { the tests were carried out in accordance with the PN-EN ISO } 90162021 \text { standard. }\end{array}$ \\
\hline 5. & $\begin{array}{l}\text { Microhardness-Vickers } \\
\text { method }\end{array}$ & $\begin{array}{l}\text { - } \quad \text { was carried out using the Zwick/Roell ZHV-30S hardness tester (ZwickRoell GmbH, Ulm, Germany); } \\
\sqrt{ } \quad \text { the tests were carried out in accordance with the PN-EN ISO 6507-01:2018-05, the hardness was } \\
\text { measured } 3 \text { times in all tested zones of a joint. }\end{array}$ \\
\hline 6. & Tensile and fatigue tests & $\begin{array}{l}\text { - } 8874 \text { Instron servo-hydraulic testing machine (Instron, High Wycombe, UK) and mini-specimens at } \\
\text { room temperature; }\end{array}$ \\
\hline & & $\sqrt{ } \quad$ the tests were carried out in accordance with the PN-EN ISO 6892-1:2020 and ASTM E468-18, respectively. \\
\hline
\end{tabular}

\subsection{Details of Static and Fatigue Tests}

Concerning directly examining the weld at the width of $0.5 \mathrm{~mm}$ under loading, the used specimens were in a mini-scale. They possessed the U-shaped working zone with the welded region in the middle of the zone considered, Figure 2a. This kind of specimen has enabled examining the weld directly under loading and following easy degradation of the region tested. Moreover, the specimen shape reduces the influence of the surface quality of the surrounding regions on results. All tests were carried out at room temperature using the 8874 Instron servo-hydraulic testing machine, Figure $2 b$,c. Mini-specimens were directly mounted in the grips and loaded. For the small distance between the upper and lower grip, the extensometer technique was not used. The following sensors of the testing machine were employed: load cell and displacement straight edge.

For the micro-jet cooled welds, the fatigue experiments were used to determine some differences between the joints. The results from these tests were selected for extending the knowledge on the behavior of joints type examined, collecting differences for indicating the strongest and weakest weld. Therefore, the fatigue test contained two stages. The first one, in the case of the base materials, was designed for values of proportional limit and ultimate tensile strength (Figure 3a). In the case of the welds, the yield stress and ultimate tensile strength were taken as an initial and final point for the cyclic sinusoidal stress signal 
(Figure $3 b-d$ ). The value of ultimate tensile strength was indicated as the amplitude at the last point of the cyclic course defined by a value of time (Table 3).

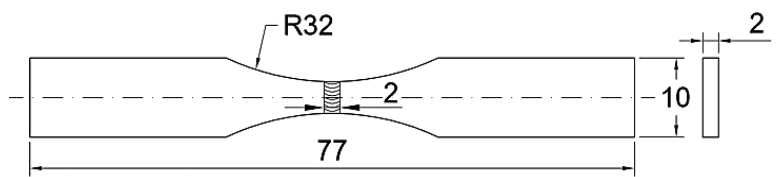

(a)

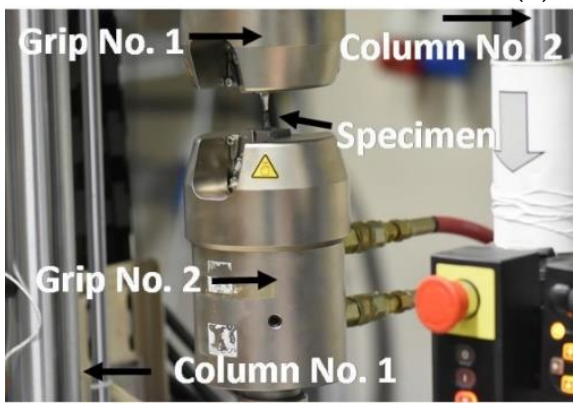

(b)

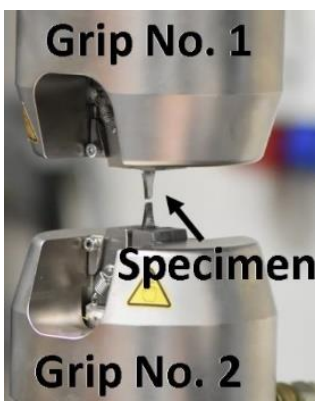

(c)

Figure 2. U-notched mini-specimen in the 8874 Instron testing machine: (a) shape and dimensions (in $\mathrm{mm}$ ) of the specimen, (b) general view and (c) mini-specimen and grips.

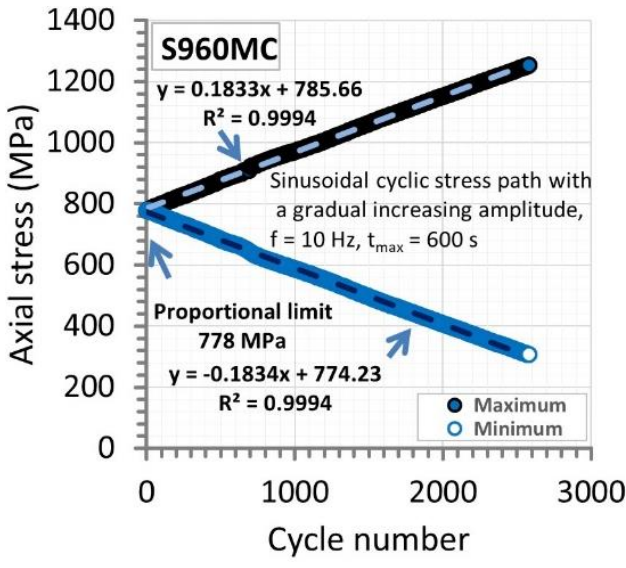

(a)

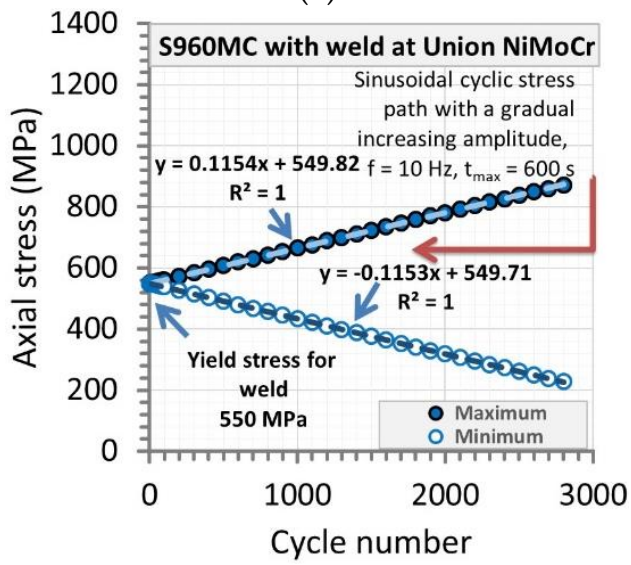

(c)

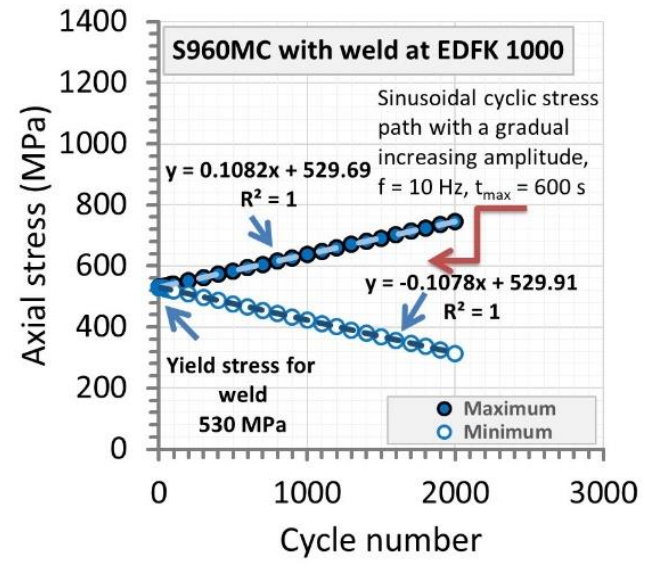

(b)

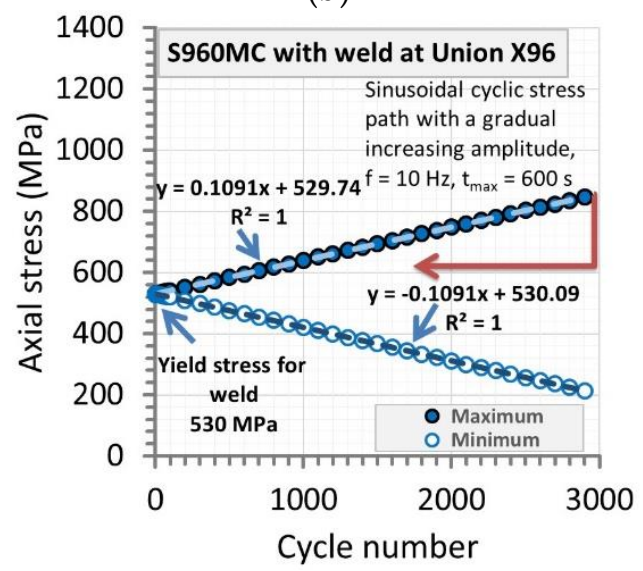

(d)

Figure 3. Courses of minimum and maximum values of axial stress amplitude from a test on the S960MC (a) and microjet cooling welds of the material manufactured at the following welding wires: (b) EDFK 1000, (c) Union NiMoCr and (d) Union X96. 
Table 3. Details in the form of mechanical parameters of the welds to experiment under increasing stress amplitude.

\begin{tabular}{|c|c|c|c|c|}
\hline No. & Specimen & $\begin{array}{l}\text { Yield Stress } \\
\text { (MPa) }\end{array}$ & $\begin{array}{c}\text { Ultimate Tensile Strength } \\
\text { (MPa) }\end{array}$ & $\begin{array}{l}\text { Time for the Envelop } \\
\text { (s) }\end{array}$ \\
\hline 1. & Weld at EDFK 1000 & 530 & 660 & \\
\hline 2. & Weld at Union NiMoCr & 550 & 700 & 600 \\
\hline 3. & Weld at Union X96 & 530 & 660 & \\
\hline
\end{tabular}

The selected value of time to fracture under the stress cycles was represented by $600 \mathrm{~s}$. This was directly used in the Envelop section for cyclic signals in the Wave Matrix software of the 8874 Instron servo-hydraulic testing machine. In all cases, the frequency was equal to $10 \mathrm{~Hz}$. In all experimental efforts, the value of yield stress was reached at the same time; next, the stress cycles were conducted at an increasing value of stress amplitude at the minimum and maximum values in a range of time 0-600 s (Figure 3). The tests were conducted up to specimen fracture starting from the value of yield stress.

Fatigue tests on the Wöhler's curve were conducted at stress signal in the form of a sinusoidal function at frequency $10 \mathrm{~Hz}$; stress ratio $\mathrm{R}=0.1$ and values of amplitude as follows: $650 \mathrm{MPa}, 600 \mathrm{MPa}, 550 \mathrm{MPa}, 500 \mathrm{MPa}, 400 \mathrm{MPa}, 300 \mathrm{MPa}, 200 \mathrm{MPa}$ and $100 \mathrm{MPa}$ (Figure 4).

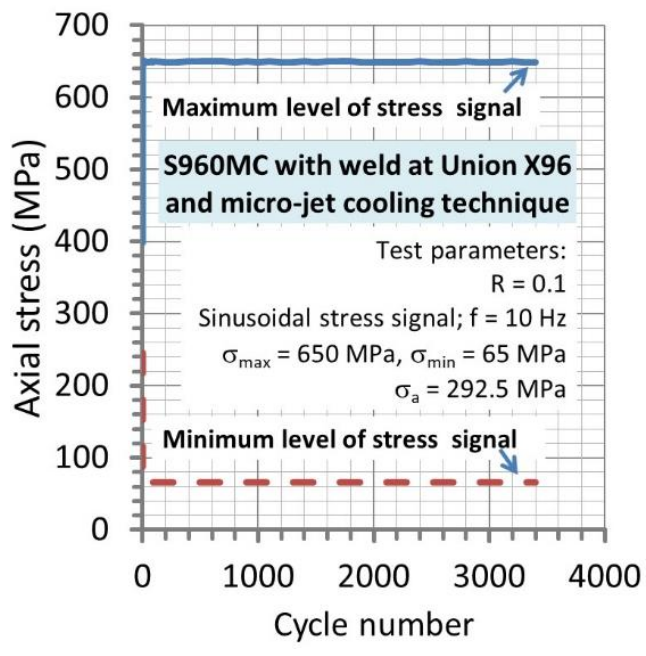

(a)

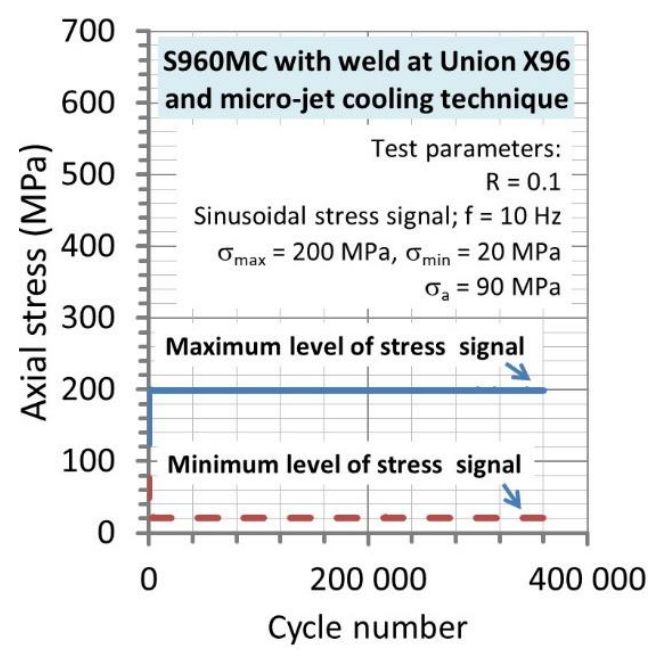

(b)

Figure 4. Maximum and minimum values of stress signals used for determining the Wöhler curve of the joint from the welding process supported by the micro-jet technique at the Union X96 welding wire: (a) the highest and (b) the lowest stress range applied in the test.

\section{Results and Discussion}

\subsection{The Results of Non-Destructive Tests}

Non-destructive test (NDT) results are presented in Table 4. The results of NDT tests allow for a preliminary assessment of the quality of the weld. They expressed differences in the weld quality and indicate the NDT is very important for determining the quality of the zone examined because defects such as cracks can be evidenced. 
Table 4. The assessment of non-destructive testing on the movable platform joint.

\begin{tabular}{|c|c|c|c|c|c|c|}
\hline Designation & Shielding Gas & $\begin{array}{c}\text { Wire, } \\
\text { C Amount (\%) }\end{array}$ & $\begin{array}{c}\text { Micro-Jet Stream } \\
\text { Pressure } \\
(\mathrm{MPa})\end{array}$ & $\begin{array}{c}\text { Micro-Jet Stream } \\
\text { Diameter } \\
(\mu \mathrm{m})\end{array}$ & $\begin{array}{l}\text { Micro-Jet } \\
\text { Gas }\end{array}$ & $\begin{array}{l}\text { Observation } \\
\text { Acceptability: } \\
(\times \text { or } \sqrt{ }, \mathrm{B}){ }^{*}\end{array}$ \\
\hline UNm1 & $\mathrm{Ar}+18 \% \mathrm{CO}_{2}$ & Union NiMoCr, (0.08) & without & without & without & $\times$ \\
\hline $\mathrm{UNm} 2$ & $\mathrm{Ar}+18 \% \mathrm{CO}_{2}$ & Union $\mathrm{NiMoCr},(0.08)$ & 0.6 & 60 & $\mathrm{Ar}$ & $\times$ \\
\hline UNm3 & $\mathrm{Ar}+18 \% \mathrm{CO}_{2}$ & Union $\mathrm{NiMoCr},(0.08)$ & 0.7 & 60 & $\mathrm{Ar}$ & $\sqrt{ }, \mathrm{B}$ \\
\hline $\mathrm{UNm} 4$ & $\mathrm{Ar}+18 \% \mathrm{CO}_{2}$ & Union NiMoCr, (0.08) & 0.6 & 70 & $\mathrm{Ar}$ & $\sqrt{ }, \mathrm{B}$ \\
\hline UNm5 & $\mathrm{Ar}+18 \% \mathrm{CO}_{2}$ & Union $\mathrm{NiMoCr},(0.08)$ & 0.7 & 70 & $\mathrm{Ar}$ & $x$ \\
\hline EDm1 & $\mathrm{Ar}+18 \% \mathrm{CO}_{2}$ & ED-FK 1000, (0.09) & without & without & without & $x$ \\
\hline EDm2 & $\mathrm{Ar}+18 \% \mathrm{CO}_{2}$ & ED-FK 1000, (0.09) & 0.6 & 60 & $\mathrm{Ar}$ & $x$ \\
\hline EDm3 & $\mathrm{Ar}+18 \% \mathrm{CO}_{2}$ & ED-FK 1000, (0.09) & 0.7 & 60 & $\mathrm{Ar}$ & $\sqrt{ }, B$ \\
\hline EDm4 & $\mathrm{Ar}+18 \% \mathrm{CO}_{2}$ & ED-FK 1000, (0.09) & 0.6 & 70 & $\mathrm{Ar}$ & $\sqrt{ }, \mathrm{B}$ \\
\hline EDm5 & $\mathrm{Ar}+18 \% \mathrm{CO}_{2}$ & ED-FK 1000, (0.09) & 0.7 & 70 & $\mathrm{Ar}$ & $\times$ \\
\hline UXm1 & $\mathrm{Ar}+18 \% \mathrm{CO}_{2}$ & Union X96, (0.11) & without & without & without & $x$ \\
\hline UXm2 & $\mathrm{Ar}+18 \% \mathrm{CO}_{2}$ & Union X96, (0.11) & 0.6 & 60 & $\mathrm{Ar}$ & $\times$ \\
\hline $\mathrm{UXm} 3$ & $\mathrm{Ar}+18 \% \mathrm{CO}_{2}$ & Union X96, (0.11) & 0.7 & 60 & $\mathrm{Ar}$ & $\sqrt{ }, \mathrm{B}$ \\
\hline UXm4 & $\mathrm{Ar}+18 \% \mathrm{CO}_{2}$ & Union X96, (0.11) & 0.6 & 70 & $\mathrm{Ar}$ & $\sqrt{ }, \mathrm{B}$ \\
\hline UXm5 & $\mathrm{Ar}+18 \% \mathrm{CO}_{2}$ & Union X96, (0.11) & 0.7 & 70 & $\mathrm{Ar}$ & $\times$ \\
\hline $\mathrm{UNc1}$ & $\mathrm{CO}_{2}$ & Union $\mathrm{NiMoCr},(0.08)$ & without & without & without & $x$ \\
\hline UNc2 & $\mathrm{CO}_{2}$ & Union $\mathrm{NiMoCr},(0.08)$ & 0.6 & 60 & $\mathrm{Ar}$ & $x$ \\
\hline UNc3 & $\mathrm{CO}_{2}$ & Union $\mathrm{NiMoCr},(0.08)$ & 0.7 & 60 & $\mathrm{Ar}$ & $x$ \\
\hline UNc4 & $\mathrm{CO}_{2}$ & Union NiMoCr, (0.08) & 0.6 & 70 & $\mathrm{Ar}$ & $\sqrt{ }, \mathrm{B}$ \\
\hline UNc5 & $\mathrm{CO}_{2}$ & Union $\mathrm{NiMoCr},(0.08)$ & 0.7 & 70 & $\mathrm{Ar}$ & $x$ \\
\hline EDc1 & $\mathrm{CO}_{2}$ & ED-FK 1000, (0.09) & without & without & without & $x$ \\
\hline EDc2 & $\mathrm{CO}_{2}$ & ED-FK 1000, (0.09) & 0.6 & 60 & $\mathrm{Ar}$ & $x$ \\
\hline EDc3 & $\mathrm{CO}_{2}$ & ED-FK 1000, (0.09) & 0.7 & 60 & $\mathrm{Ar}$ & $\sqrt{ }, \mathrm{B}$ \\
\hline EDc4 & $\mathrm{CO}_{2}$ & ED-FK 1000, (0.09) & 0.6 & 70 & $\mathrm{Ar}$ & $\times$ \\
\hline EDc5 & $\mathrm{CO}_{2}$ & ED-FK 1000, (0.09) & 0.7 & 70 & $\mathrm{Ar}$ & $x$ \\
\hline UXc1 & $\mathrm{CO}_{2}$ & Union X96, (0.11) & without & without & without & $x$ \\
\hline UXc2 & $\mathrm{CO}_{2}$ & Union X96, (0.11) & 0.6 & 60 & $\mathrm{Ar}$ & $x$ \\
\hline UXc3 & $\mathrm{CO}_{2}$ & Union X96, (0.11) & 0.7 & 60 & $\mathrm{Ar}$ & $x$ \\
\hline UXc4 & $\mathrm{CO}_{2}$ & Union X96, (0.11) & 0.6 & 70 & $\mathrm{Ar}$ & $x$ \\
\hline UXc5 & $\mathrm{CO}_{2}$ & Union X96, (0.11) & 0.7 & 70 & $\mathrm{Ar}$ & $\times$ \\
\hline
\end{tabular}

* Board description: $\sqrt{ }, \mathrm{B}-$ No cracks in the weld, level of quality-B without welding defects and incompatibilities; $\times$-Cracks in the weld.

Based on the results of non-destructive testing, the samples in Table 4 were marked as " $\sqrt{ }$ " - positive and " $\times$ " -negative. Examples of non-destructive testing results are shown in Figures 5 and 6 . Figure 5 shows a positive result recorded for sample UXm3. The quality of the sample was on level B. No cracks and welding incompatibilities were found in the analyzed joint. Figure 6 shows a negative result. The result was obtained for sample UXm1, which is characterized by welding incompatibilities.

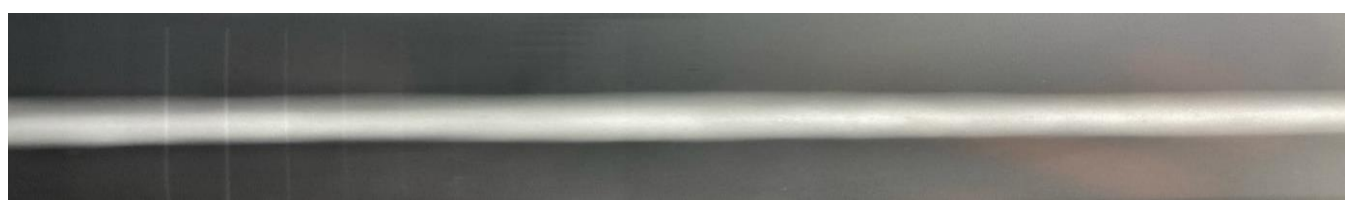

Figure 5. Correctly made joint after welding with micro-jet cooling. 


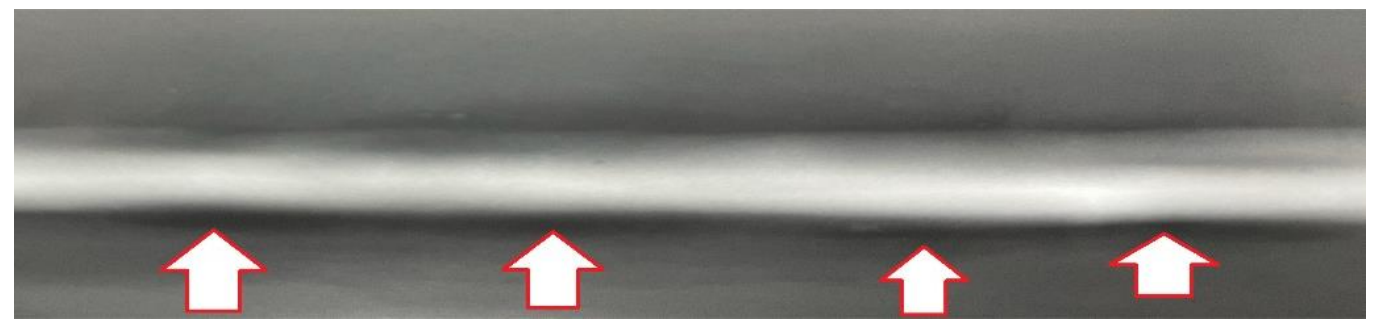

Figure 6. Welding defects (cracks) and incompatibilities after classic MAG welding without micro-jet cooling.

MAG welding in $\mathrm{CO}_{2}$ shield is more oxidizing than welding in an $\mathrm{Ar}-18 \% \mathrm{CO}_{2}$ shield. Welding in a $\mathrm{CO}_{2}$ shield corresponds to the oxygen content in the weld at the level of $500 \mathrm{ppm}$, which translates into the larger size of non-metallic inclusions that may initiate cracks. Welding in the Ar- $\mathrm{CO}_{2}$ mixture shield is less oxidizing; it leads to the formation of smaller non-metallic inclusions that may, to a lesser extent, cause cracks in the joint. The classification of welding processes in terms of the oxygen content in the weld and its justification was presented in 1999 [29,30].

Based on the analysis of the table data, it can be noticed that the M21 mixture (Ar + $\left.18 \% \mathrm{CO}_{2}\right)$ is much better than $\mathrm{CO}_{2}$. From the analysis of the results presented in Table 4, it follows that the test was carried out correctly; the evaluation of the tests is positive only in some cases when micro-jet cooling was not too intense and not too weak. For further tests (destructive test-DT), only those joints that met these requirements were taken into account:

- made with the use of micro-jet cooling;

- no cracks were observed.

Therefore, samples with the following determinations were taken into account (UNm3, UNm4, EDm3, Edm4, UXm3, UXm4 and UNc4, EDc3).

\subsection{Data from the Bending and Hardness Tests}

The test results of bending tests are summarized in Table 5. The process was correct only with medium-power micro-jet cooling because no cracks and other disconformities were found in the samples tested. It reflected the high-quality level of the joint, and it was confirmed in comparison to the regimes of the PN-EN ISO 5817 standard [31] on a crack length $\geq 0.5 \mathrm{~mm}$ at the highest requirement. Sample section dimension: $2 \mathrm{~mm} \times 20 \mathrm{~mm}$.

Table 5. Bending tests results.

\begin{tabular}{|c|c|c|}
\hline Sample & Deformed Side & Observation * \\
\hline $\mathrm{UNm} 3$ & root & $\sqrt{ }$ \\
\hline UNm3 & face & $\sqrt{ }$ \\
\hline UNm4 & root & $\sqrt{ }$ \\
\hline UNm4 & face & $\sqrt{ }$ \\
\hline EDm3 & root & $\sqrt{ }$ \\
\hline EDm3 & face & $\sqrt{ }$ \\
\hline EDm4 & root & $\sqrt{ }$ \\
\hline EDm4 & face & $\sqrt{ }$ \\
\hline $\mathrm{UXm} 3$ & root & $\sqrt{ }$ \\
\hline UXm3 & face & $\sqrt{ }$ \\
\hline UXm4 & root & $\sqrt{ }$ \\
\hline UXm4 & face & $\sqrt{ }$ \\
\hline UNc4 & root & $x$ \\
\hline UNc4 & face & $\times$ \\
\hline EDc3 & root & $x$ \\
\hline EDc3 & face & $\times$ \\
\hline
\end{tabular}


The bending tests confirmed that after welding with micro-jet cooling, it is possible to achieve joints with good plastic properties, as measured by the absence of cracks. In addition to the use of micro-jet cooling, the type of shielding gas plays an important role. Only the use of the $\mathrm{Ar}-\mathrm{CO}_{2}$ mixture allows obtaining the correct joints.

\subsection{Metallographic Examination and Hardness}

Microstructure observations were carried out on the Neophot 32 light microscope (Carl Zeiss Jena, Jena, Germany). The structure is dominated by martensite and ferrite. Figure 7 shows the structure observed in the UXm3 sample. Generally, martensite and coarse-grained ferrite were observed.

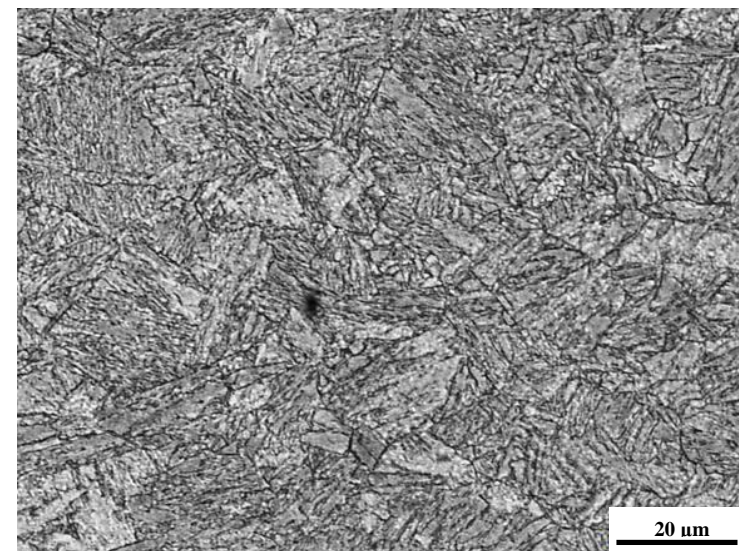

Figure 7. The microstructure of the joint $(\mathrm{UXm} 3)$ with visible martensite and course ferrite (LMLight Microscopy).

Only the application of micro-jet cooling after MAG welding made it possible to obtain more fragmented phases: martensite and ferrite (shown in Figure 8). This is due to micro-jet cooling during welding, which limits phase growth during the austenitic transformation. Other authors also draw attention to the possibility of grain fragmentation because of the use of micro-jet cooling [28,32].

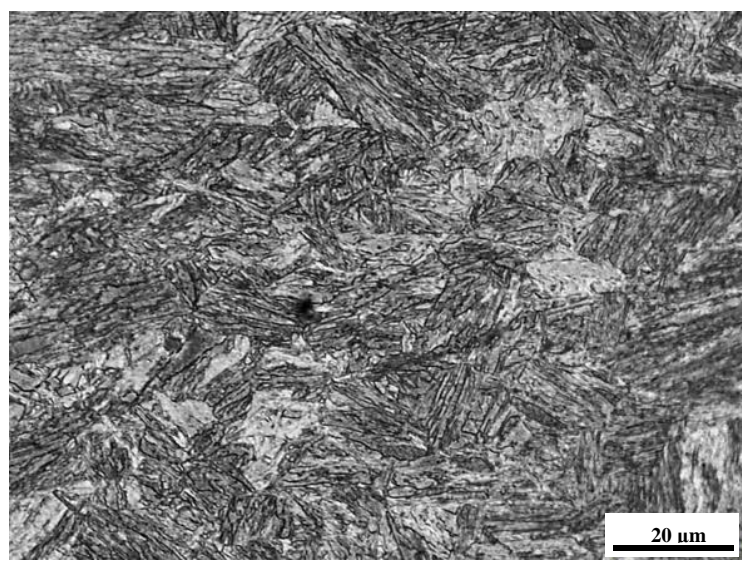

Figure 8. The microstructure of the joint (UXm3) after welding with micro-jet cooling with visible martensite and fine-grained ferrite (LM).

After microscopic observation, it was decided to perform hardness tests. It was made for the same samples. The results are presented in Table 6. 
Table 6. The hardness of the joint (UXm3).

\begin{tabular}{cccccccccc}
\hline MAG Process & \multicolumn{3}{c}{ Base Material } & \multicolumn{3}{c}{ HAZ } & \multicolumn{3}{c}{ Weld } \\
\hline With m-j cooling & 334 & 336 & 337 & 354 & 349 & 351 & 327 & 329 & 332 \\
Without m-j cooling & 338 & 335 & 339 & 371 & 369 & 373 & 341 & 342 & 344 \\
\hline
\end{tabular}

The table data shows that a more favorable and even distribution of hardness in all tested zones is for a joint made with micro-jet cooling.

\subsection{The Steel and Its Micro-Jet Cooled Joint at Different Welding Wire in a Static Test}

S960MC steel appears as the material having elastic-plastic with hardening and unstable regions (Figure 9). The proportion between ultimate tensile strength (UTS) and yield stress (YS) reached the value of 1.11, expressing the small distance between the mechanical parameters considered. From the practical point of view, this feature indicates an inspection of the element made of this kind of steel if the stress has equaled yield stress during operation. Another important sign in the S960MC behavior under tensile stress is evidenced in a region of the unstable section, which dominates in $70 \%$ comparing to the elastic and elastic-plastic with hardening zones. This informs the steel can carry loading at a long moment after a value of stress exceeds ultimate tensile strength. Taking the long unstable section, the steel can be easy to diagnose at high values of stress without any difficulties and risks for researchers, engineers and diagnostics teams. This sentence is also confirmed by a value of stress at the steel rupture, i.e., $600 \mathrm{MPa}$, indicating two times difference comparing to the value of ultimate tensile strength and distancing the fracture up to a value of a relative elongation of $9.5 \%$. The behavior of the steel follows advantages concerning the application of this kind of material in a tri-axial stress state because the necking effect is significant, and this prevents brittle cracking.

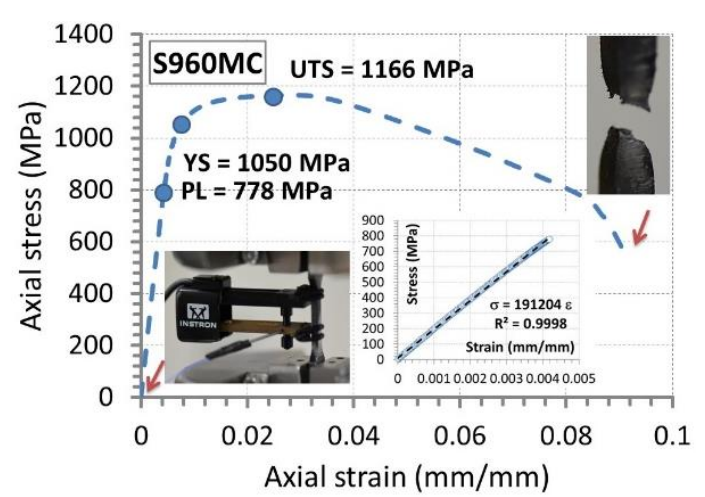

(a)

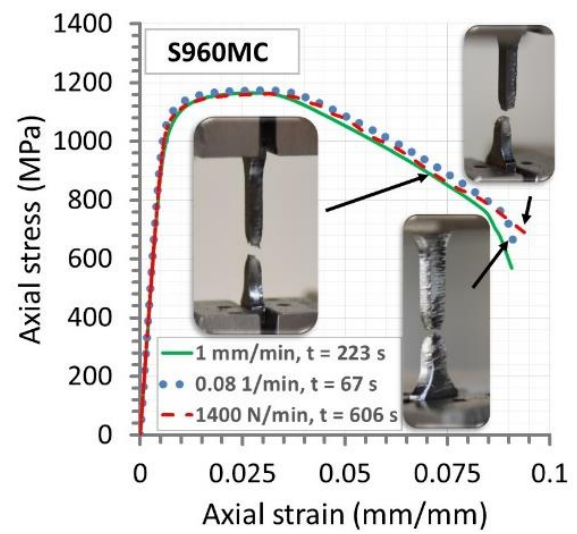

(b)

Figure 9. The tensile characteristic of S960MC steel (a) and its variations (b) due to three different signals used in the tensile test: displacement at velocity of $1 \mathrm{~mm} / \mathrm{min}$, strain at $0.081 / \mathrm{min}$ and stress reaching $117 \mathrm{MPa} / \mathrm{min}$, proportional limit $(\mathrm{PL})=778 \mathrm{MPa}$, yield stress $(\mathrm{YS})=1050 \mathrm{MPa}$, ultimate tensile strength $(\mathrm{UTS})=1166 \mathrm{MPa}$ and elongation $8.75 \%$.

The advantages of the S960MC steel are captured at tensile stress conducted at various types of control signals represented by the following velocity values of displacement, strain and stress signals such as $1 \mathrm{~mm} / \mathrm{min}, 0.08 \mathrm{~L} / \mathrm{min}$ and $117 \mathrm{MPa} / \mathrm{min}$, respectively (Figure 9). As it can be noticed, the stress-strain curves follow the same course, which expresses insensitivity of the steel tested on the type of tensile signal and the time up to fracture related to the control kind used. This enables to sentence the mechanical parameters of the steel are stable for the wide range of loading signals and their parameters, extending the application of the material examined to operational conditions with different velocity diverse by even 10 times. 
The steel behavior as a parent material was also dominant compared to welded joints manufactured by the micro-jet cooling technique (Figure 10). The most differences were visible for all stress parameters, placing the steel as a very attractive material compared to its weld. Nevertheless, the data collected for the micro-jet cooled weld enable to indicate advantages of the joint at the loading type considered. As a first, an attractive value of ultimate tensile strength of $650 \mathrm{MPa}$ at all welding wires used can be evidenced. A second feature of the weld is related to a value of relative elongation because, at the fracture, the parameter reached $12.5 \%$ for the EDFK wire. This result and a range of the unstable regions enable to formulate sentences related to the application in a tri-axial stress state, i.e., the micro-jet cooled weld behavior after the necking effect is predictable and will be the same for all joints considered. No influence of the welding wire type on the joint's response was also visible in the elastic and elastic-plastic regions, following almost the same values of stress-strain.

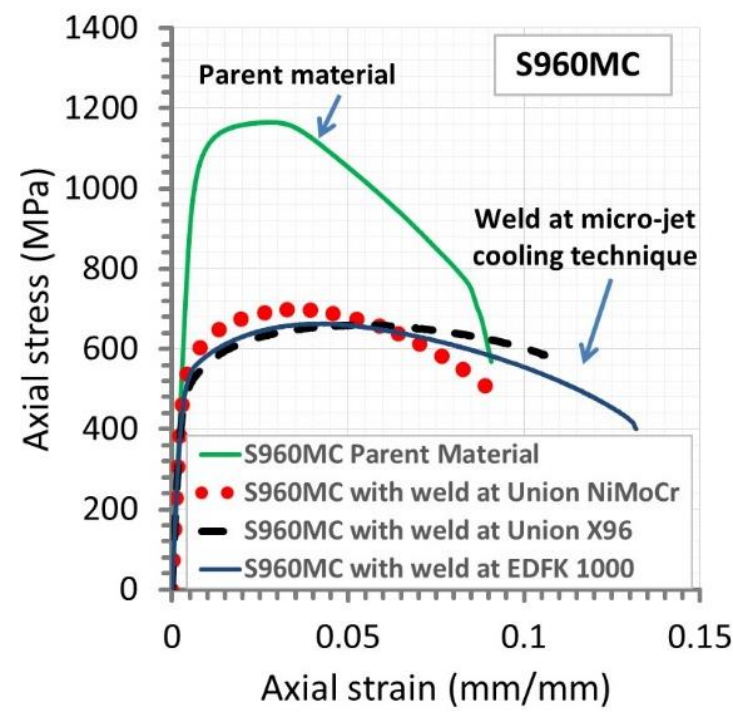

(a)

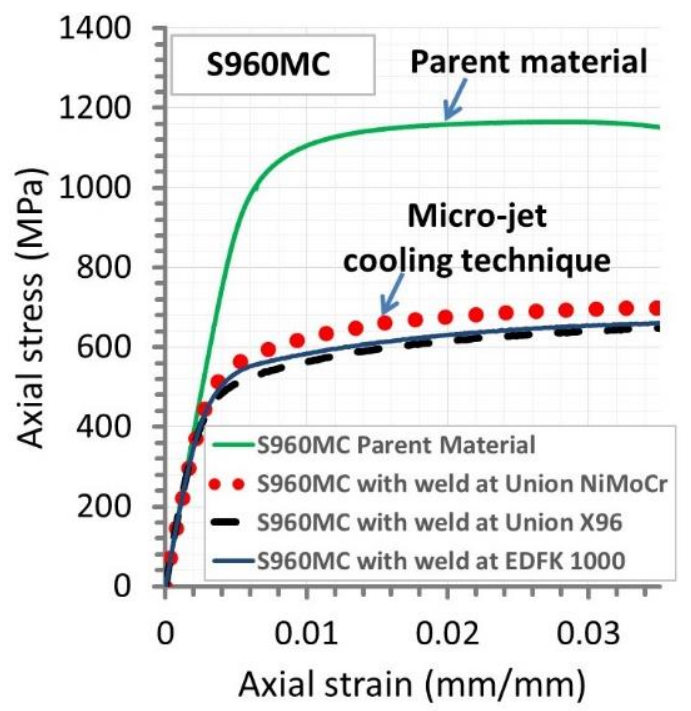

(b)

Figure 10. The tensile characteristic of S960MC steel and its weld manufactured using three welding wires at supporting the micro-jet cooling technique: (a) up to fracture, (b) in a view on the elastic and elastic-plastic relationships.

The results from tensile tests collected using mini-specimens have enabled us to follow the stress-strain relationship and mechanical parameters of the S960MC steel. This kind of specimen was also very sufficient at determining the influence of a control signal as displacement, stress, and strain. Literature $[17,19,20]$ indicates mechanical properties of weld for S960MC without any details on a specimen shape and dimensions $[17,20]$ or presents a bigger specimen, i.e., having $1000 \mathrm{~mm}$ length [19]. As it was obtained, the steel tested was not sensitive to the signal type used. The mini-specimen has supported examining the small weld, represented by the width of $0.5 \mathrm{~mm}$ under static loading, giving a tensile curve. Comparing data from the experiment on the base metal and welds has allowed us to distinguish differences in responses of the regions tested on static loading. Nevertheless, it is worth noting that the applications of small specimens require more attention during the tuning process because the measurement zone with a mounted extensometer is very close to the grips, which at inducing a testing machine can cause total damage to a sensor.

3.5. Fatigue Response of the Steel and the Micro-Jet Cooling Weld under Increasing and Constant Stress Amplitude

The behavior of the base material was expressed by hysteresis loops related to the energy dissipation as a dominant response of the material tested on the cycles used (Figure 11a). The first section of the relationship followed the elastic response of the material tested as 
an effect of hardening due to cyclic loading, while the second one was connected with permanent deformation. As it can be noticed, this feature occurred up to the cycle before the fracture. Moreover, the welds were loaded within the value of stress from the range between yield stress and ultimate tensile strength, and any hysteresis loops were not visible (Figure 11b-d). In this case, the stress-strain relationship has followed ratcheting up to fracture. This was very significant because it increased very rapidly before the fracture. As it can be noticed, this effect was the same for all cases of the welds considered, indicating the behavior of welds manufactured at the micro-jet cooling technique is insensitive to the type of welding wires used.

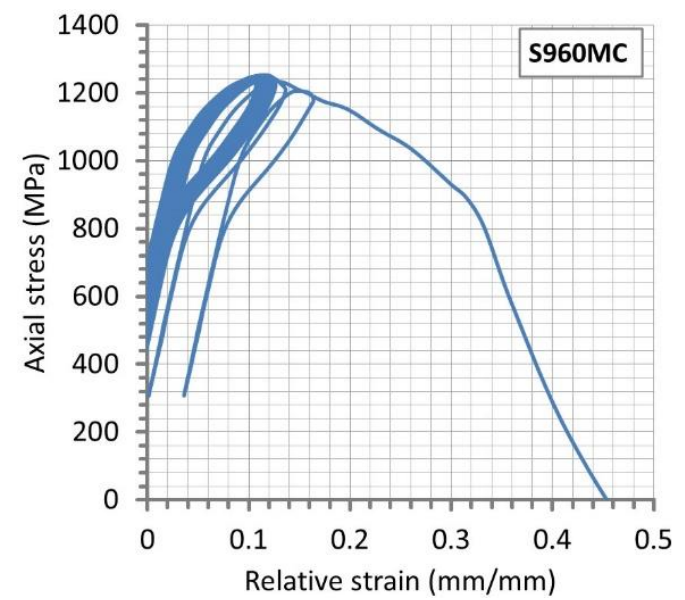

(a)

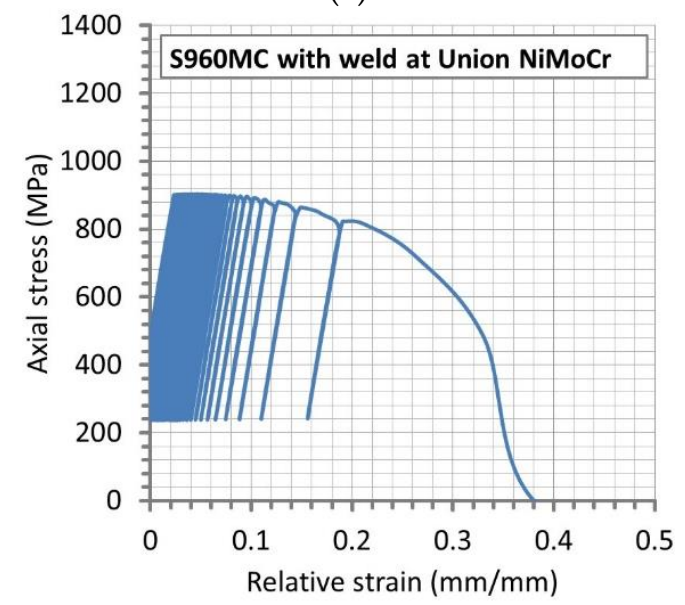

(c)

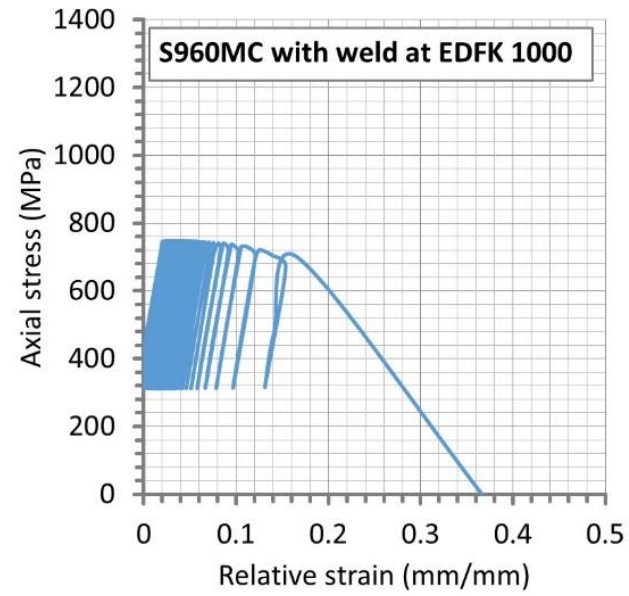

(b)

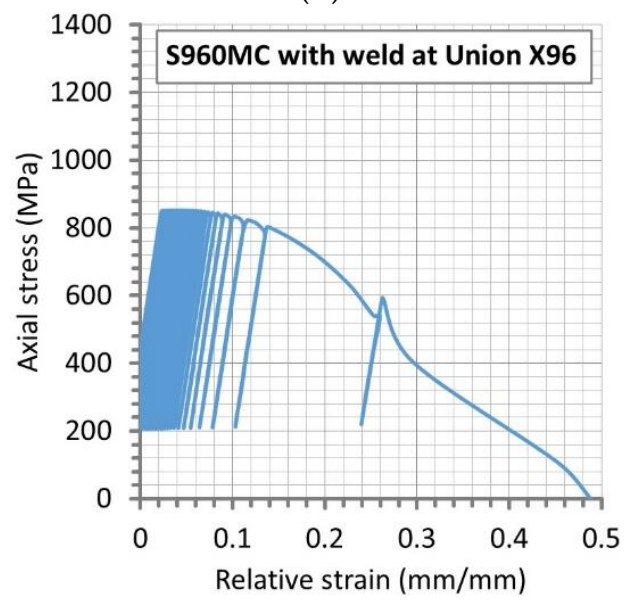

(d)

Figure 11. The stress-strain relationship at the final stages of the S960MC steel (a) and the joint welded by the micro-jet cooling and the following types of welding wires: (b) EDFK 1000, (c) Union NiMoCr and (d) Union X96.

The fatigue response of the base material under the increasing value of the stress amplitude was analyzed concerning the courses of total energy (Figures 12 and 13) because it demonstrates data representing loading signal (stress, force) and response signal (strain, elongation, displacement). The values of the physical magnitude were followed from the tests' beginning up to fracture, focusing on the last 50-th cycles directly related to the degradation of the parent material and the welds. This quantity was calculated basing on features of the Wave Matrix Instron software. It follows the total work performed on the specimen tested [33]. The values of force and displacement were used for calculations of the energy value. This parameter was followed since the start of the test. The software calculates total energy by continuously integrating force with displacement, using the trapezoidal rule [33]. 


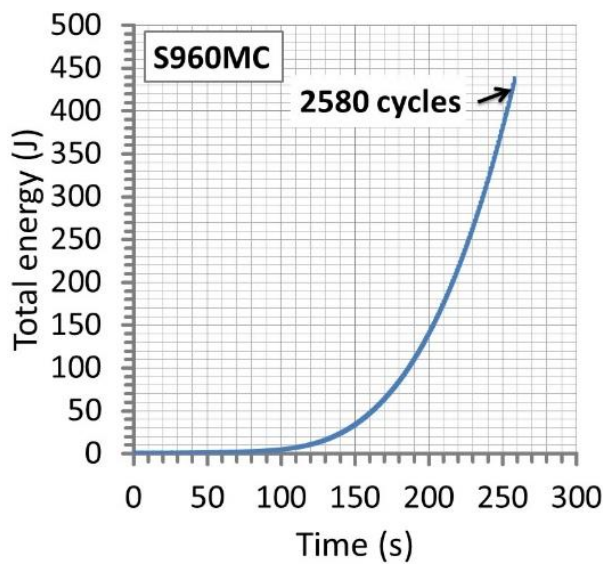

(a)

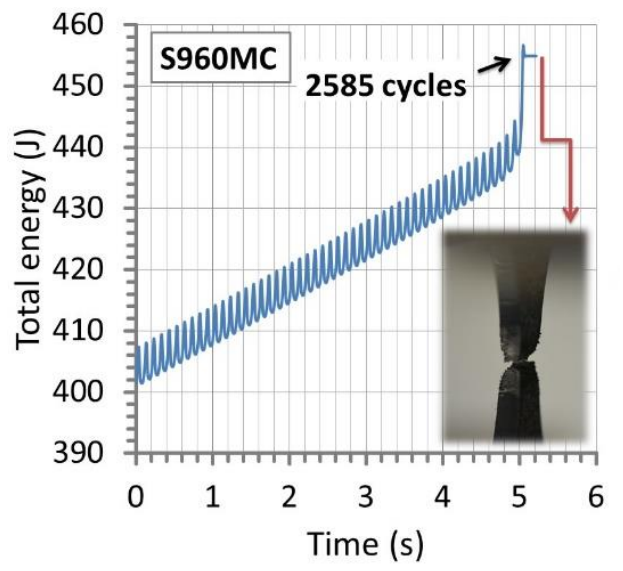

(b)

Figure 12. The total energy versus time from tests under increasing amplitude of axial stress before (a) and at the fracture (b) of S960MC steel, respectively.

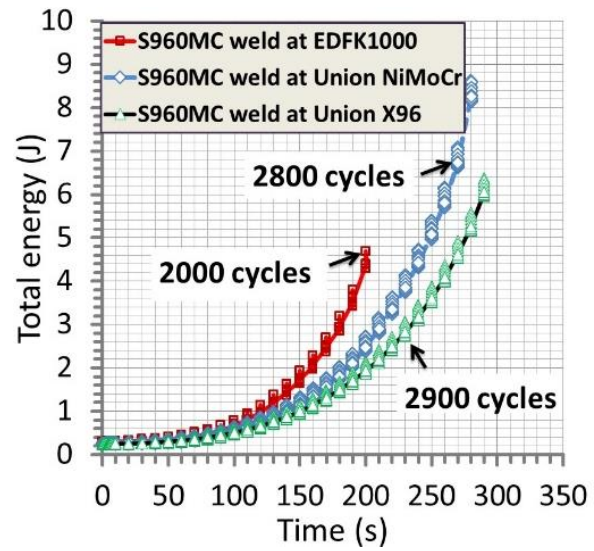

(a)

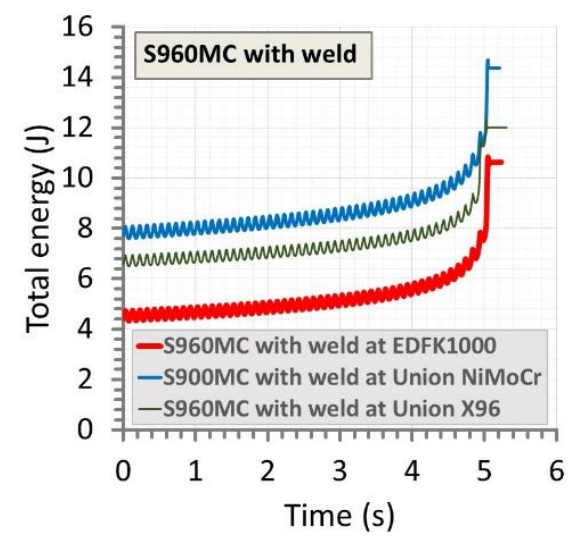

(b)

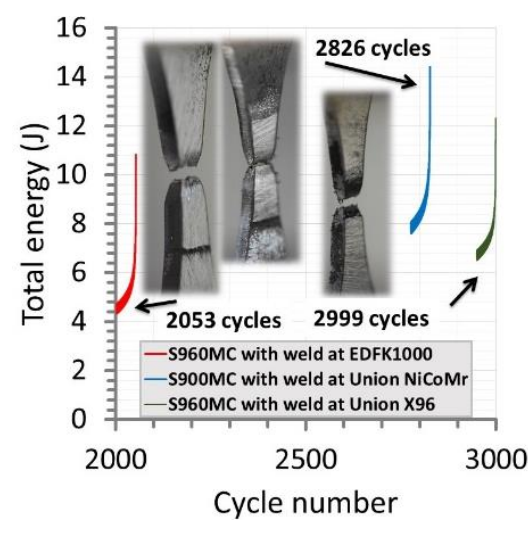

(c)

Figure 13. The total energy of the welds versus time (a), (b) before and at the fracture, respectively, and (c) the total energy versus cycle number at fracture for the three welding wires: EDFK 1000, Union NiMoCr and Union X96 for S960MC steel.

The results collected in the test considered have expressed the same tendency of the values of total energy independently on the region tested, represented by an exponential relationship (Figures 12a and 13a). Differences were visible in courses of the physical quantity, expressing not the same mechanical resistance of the welds on the type of loading applied, Figure 13a. They indicated the weld manufactured at micro-jet cooling technique and EDFK 1000 welding wires had obtained the smallest energy values while the biggest one was represented by results of the micro-jet weld at the NiMoCr wire. The same arrangement of the results was observed on the data directly related to the fracture stages of the regions tested (Figure 13b,c), values of the number of cycles, as well as the time to fracture. In the case of the base material, the value of cycles before the fracture reached 2580 at 258 s (Figure 12b), while for the welds, the following values were obtained: 2000 at $200 \mathrm{~s}$ (EDFK 1000 welding wire), 2800 at 280 s (Union NiMoCr welding wire) and 2900 at $290 \mathrm{~s}$ (Union X96 welding wire) (Figure 13a).

The results from the fracture stage in the form of the relationship of total energy versus the number of cycles have finally expressed the mechanical resistance of the welds examined (Figure 13c). The smallest one was noticed in the case of the micro-jet cooled weld with EDFK 1000 wire, and the biggest one was observed at the weld produced by the same technique but with the Union X96 wire, reaching the following values, respectively: 2053 and 2999 cycles (Table 7). This result strongly corresponds with the data presented 
in Figure 13a, which arranges the courses of the total energy in the same order. Some details on the behavior of the region tested can be captured based on the fracture zones. As it can be noticed in the photos presented in Figure 13c, the brittle cracking was the dominant feature of the weld at EDFK 1000; the brittle plastic was related to the weld at Union X96; the plastic represented the behavior of the NiMoCr joint. Nevertheless, any relationships were not observed at the comparison of the values of yield stress, ultimate tensile strength and the number of cycles connected with the fracturing of the tested joints (Figure 14a,b). Some information can be collected based on values of total energy and stress at fracture (Figure 14c,d). This is presented by the proportion of the physical quantity, which arrangements the welds with the EDFK 1000 and Union X96 welding wires as the joints with the same and the lowest mechanical resistance of the loading applied, while the weld of the Union $\mathrm{NiMoCr}$ wire become the strongest one from the joint examined.

Table 7. The results from tests under increasing stress amplitude.

\begin{tabular}{ccccc}
\hline & Specimen & \multicolumn{2}{c}{ Axial Stress at Fracture (MPa) } & \multirow{2}{*}{ Time to Fracture (s) } \\
\cline { 3 - 4 } No. & & Maximum & Minimum & \\
\hline 1. & Parent material & 1253 & 306 & 269 \\
2. & Weld at EDFK 1000 & 745 & 314 & 216 \\
3. & Weld at Union NiMoCr & 870 & 229 & 293 \\
4. & Weld at Union X96 & 846 & 214 & 310 \\
\hline
\end{tabular}

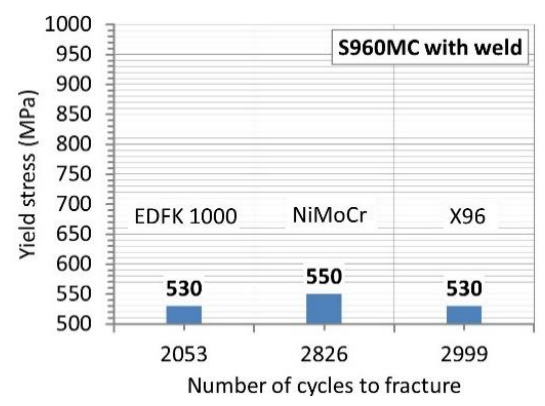

(a)

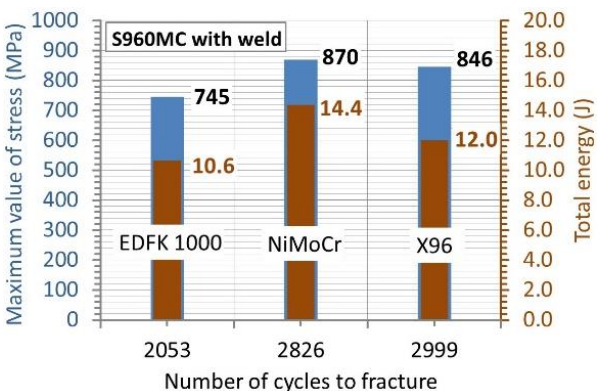

(c)

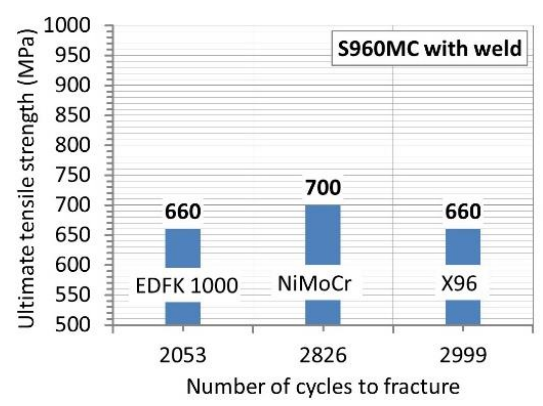

(b)

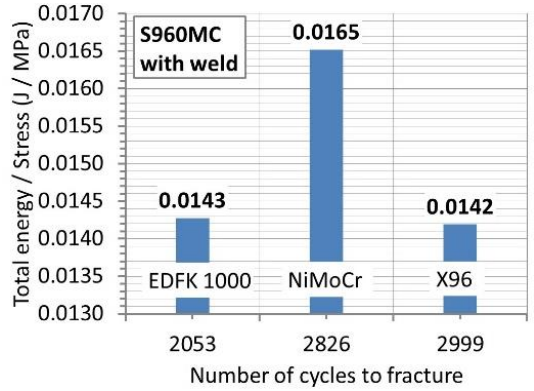

(d)

Figure 14. The yield stress (a), ultimate tensile strength (b), maximum value of stress (c) and total energy/the maximum value of stress at a number of cycles (d) up to the fracture for welds manufactured by the micro-jet cooling technique and the following welding wires: $\mathrm{NiMoCr}$ (Union), EDFK 1000 and X96 (Union).

The results from the tests under increasing stress amplitude were used for selecting the weld for determining the Wöhler curve. For this case, the joint with the Union X96 welding wire as the weakest region welded was tested under cyclic stress at the range of $650 \mathrm{MPa}-100 \mathrm{MPa}$. Data collected from the fatigue experiment are presented in the next sub-chapter.

Fatigue tests at increasing stress amplitude defined by the yield stress and ultimate tensile strength as well as a time have enabled us to distinguish differences in behavior of the welds having very similar tensile characteristics. For this case, the values of the total 
energy were also significant because they divided into two sections from the beginning of the test up to cycles before and directly at the fracture, giving more information on the regions' decohesion. This kind of test has allowed us to reach differences in fracture regions, giving more details to assess the mechanical resistance of the weld tested. Values of total energy have supported the analysis on the weld quality expressing the joints response on the cyclic loading. Their comparison with the maximum value of stress of the control signal has enabled to indicate the joints for both welding wires (EDFK 1000 and Union X96) expressed the same proportion, even though the stress levels applied as well as the number of cycles to fracture were significantly different by of $99 \mathrm{MPa}$ and 946 cycles, respectively. Concerning the assessment of the weld quality, the following sentence can be formulated: the joints were manufactured at different welding wires, but nevertheless, they have a very similar reaction to the fatigue process. Taking these results into account, the strongest and weakest joints were possible to be indicated, arranging as of NiMoCr weld, EDFK 1000 and X96 welds.

\subsection{Results from Tests of the Micro-Cooled Weld under Constant Stress Amplitude}

The results from the experiments under stress cycles are represented by variations of total energy (Figure 15a), the proportion of total energy to stress (Figure 15b), fracture regions as both parts of specimen directly after cracking (Figure 16) and as the zones on a perpendicular cross-section of the specimens (Figure 17) as well as the Wöhler curve (Figure 18).

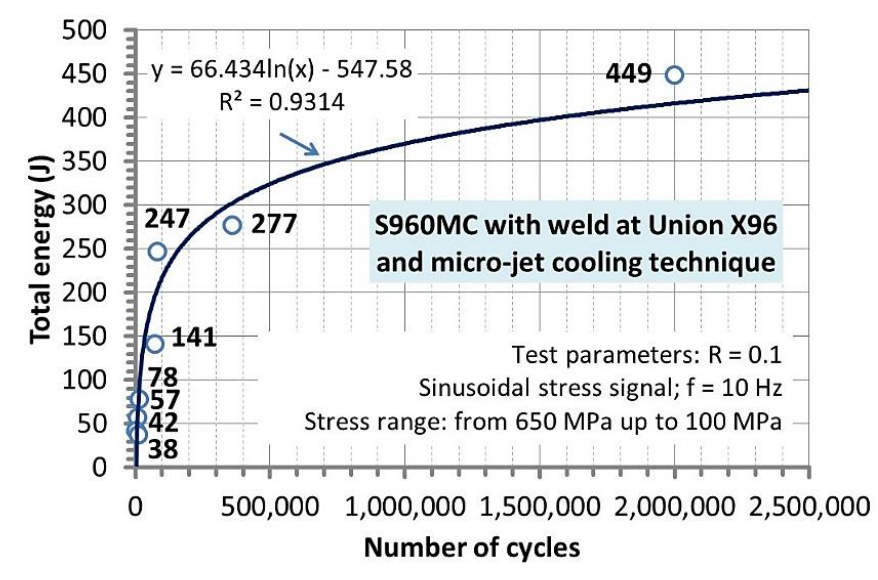

(a)

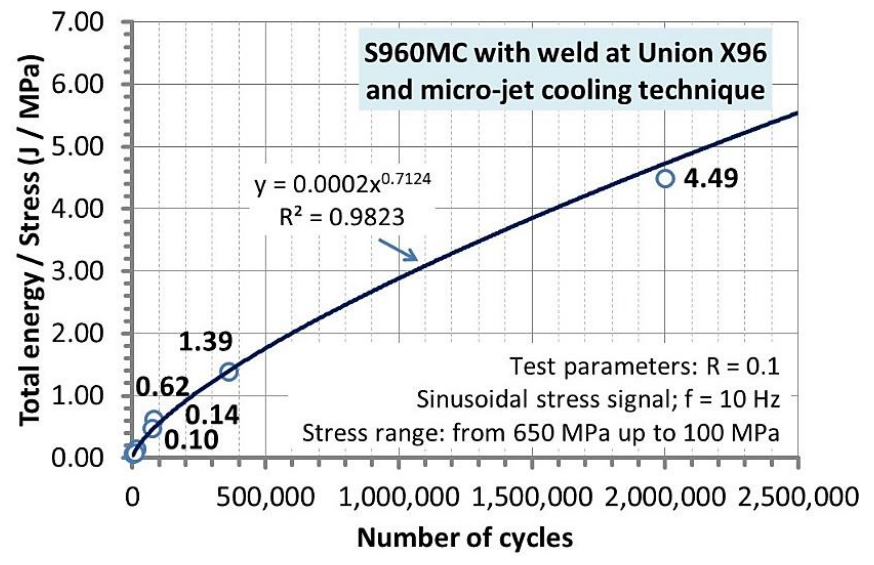

(b)

Figure 15. Total energy (a) and its value per stress (b) versus the number of cycles at the Wöhler curve of S960MC steel welded by the MAG method with the micro-jet cooling technique. 


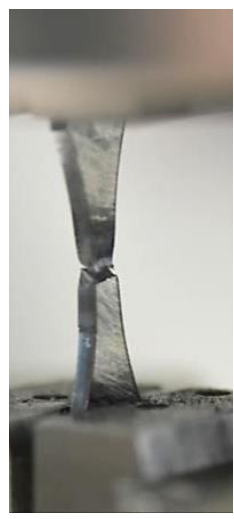

(a1)

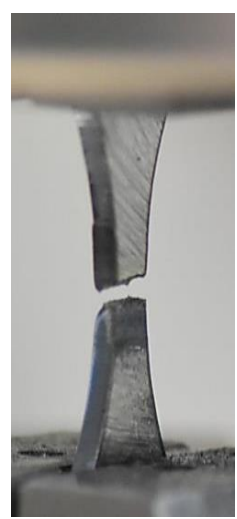

(c1)

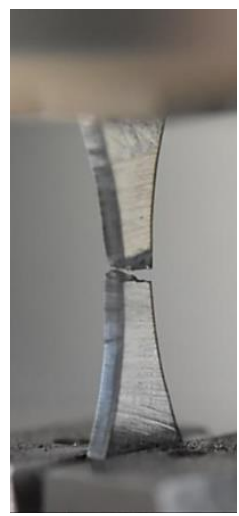

(e1)

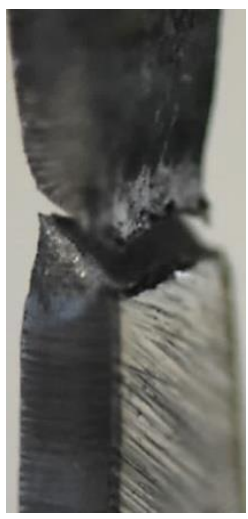

(a2)

$650 \mathrm{MPa}$

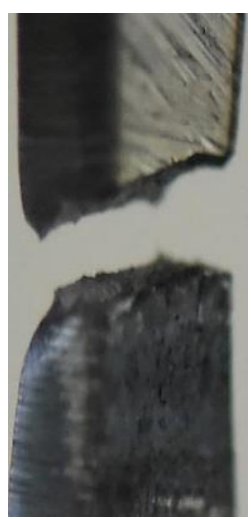

(c2)

$500 \mathrm{MPa}$

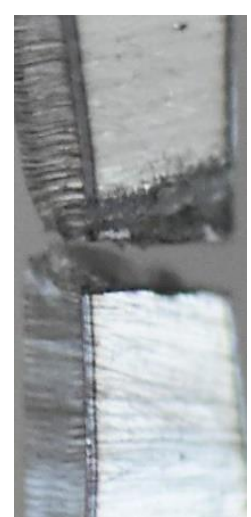

(e2)

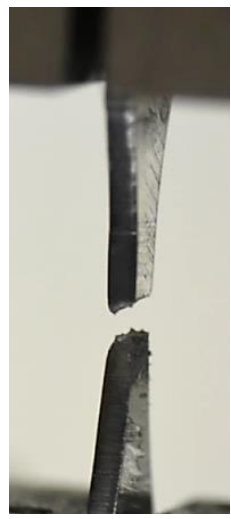

(b1)

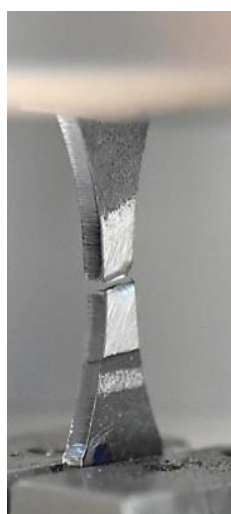

(d1)

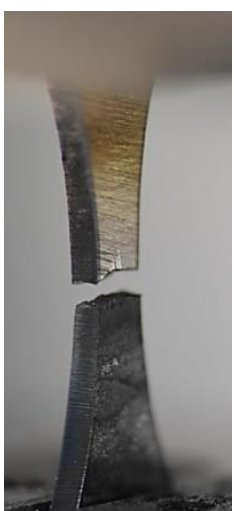

(f1)

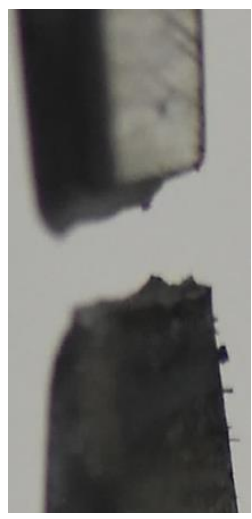

(b2)

$600 \mathrm{MPa}$

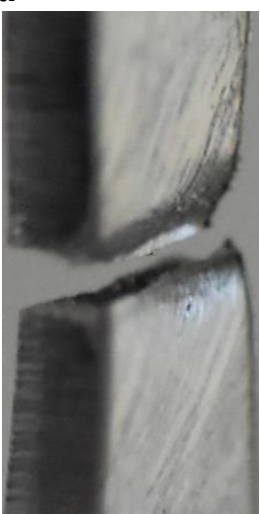

(d2)

$400 \mathrm{MPa}$

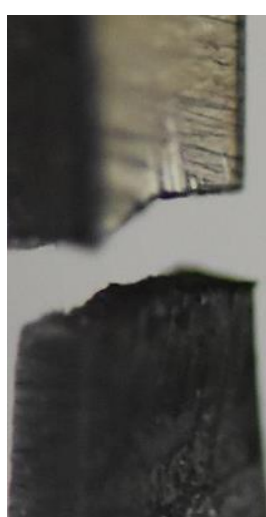

(f2)

$300 \mathrm{MPa}$

Figure 16. S960MC mini-specimens with the micro-jet cooling weld manufactured with the Union X96 welding wire after the fatigue test for the maximum values of the axial stress amplitude of $650 \mathrm{MPa}-100 \mathrm{MPa}$, (a1-f2) fracture regions. 


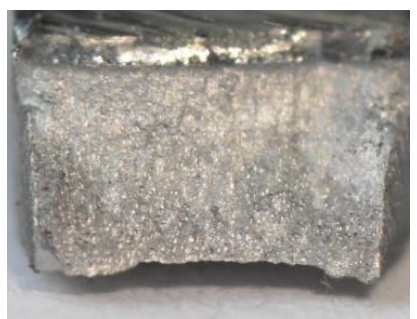

(a1)

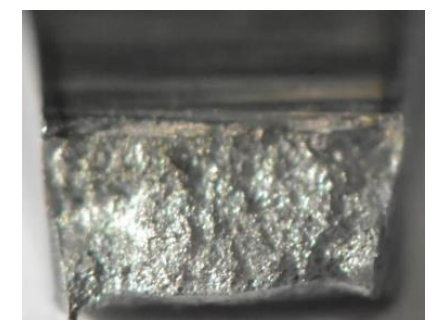

(c1)

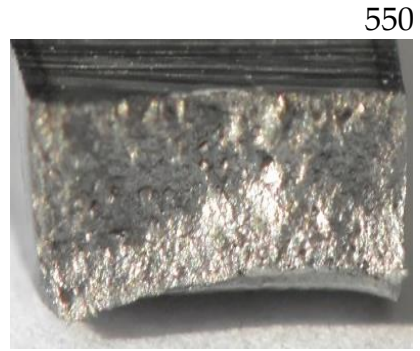

(e1)

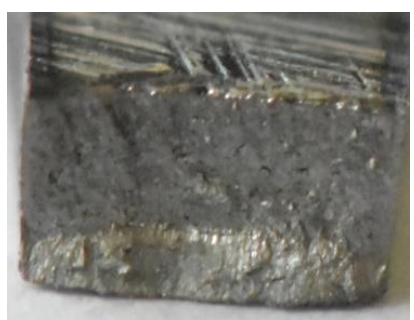

(g1)
$400 \mathrm{MPa}$

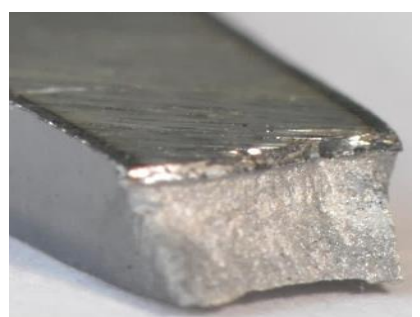

(a2)

$650 \mathrm{MPa}$

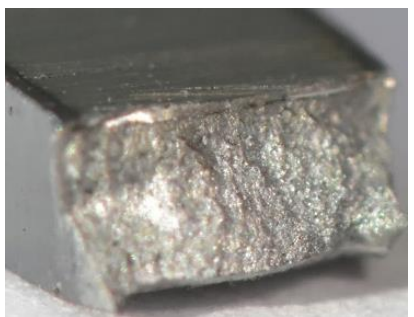

(c2)

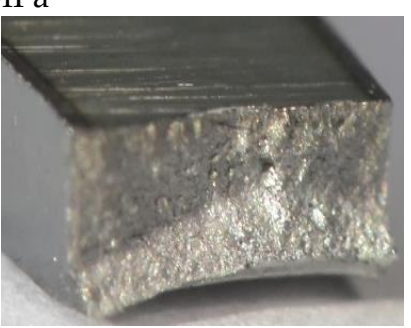

(e2)

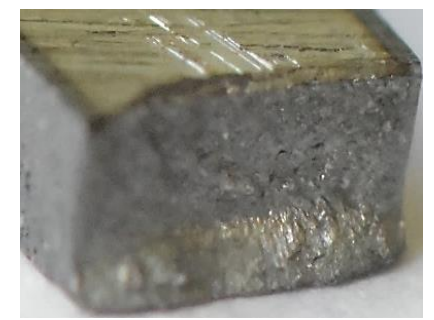

(g2)

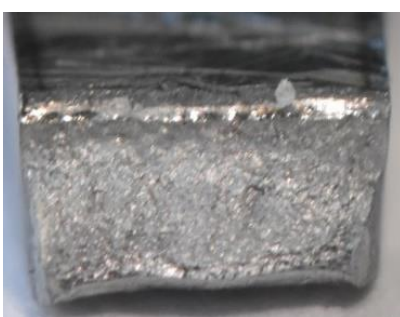

(b1)

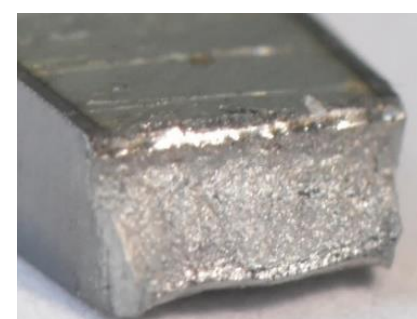

(b2)

$600 \mathrm{MPa}$

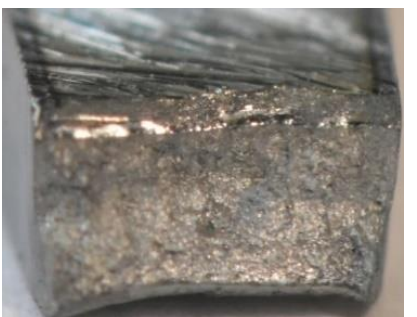

(d1)

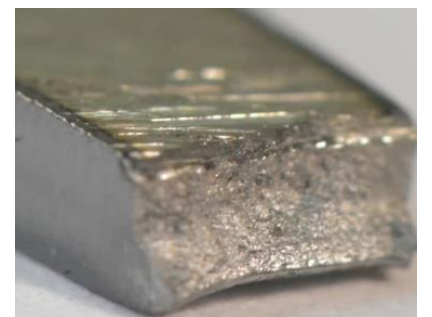

(d2)

$500 \mathrm{MPa}$

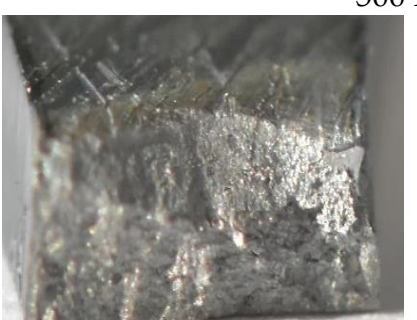

(f1)

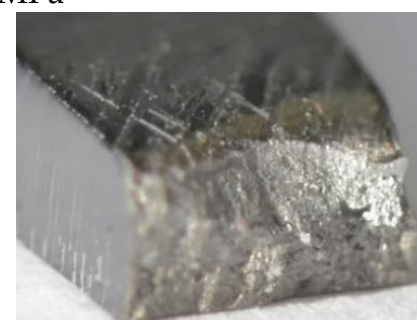

(f2)
$300 \mathrm{MPa}$

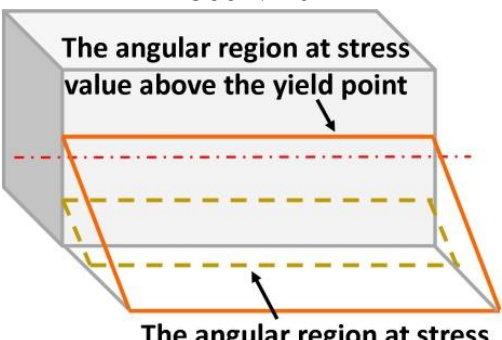

value below the yield point

(g3)

$200 \mathrm{MPa}$

Figure 17. Fracture regions (a1-g3) of S960MC weld manufactured at micro-jet cooling technique after fatigue tests for the maximum values of axial stress amplitude of $650 \mathrm{MPa}-100 \mathrm{MPa}$ and the fracture scheme (g3), number 1 represents a perpendicular view while number 2 follows an axonometric one.

They show a course of total energy up to fatigue limit at values of the number of cycles (Figure 15a). As it can be noticed at the earlier stage of the course up to $5 \times 10^{5}$, the maximum value of total energy is represented by $325 \mathrm{~J}$. For the further section reaching $1 \times 10^{6}$ cycles, the value of $375 \mathrm{~J} \mathrm{limits}$, while at the fatigue limit (determined by $2 \times 10^{6}$ ), an increase of the total energy was expressed by $95 \mathrm{~J}$ giving $420 \mathrm{~J}$. If values of total energy and stress are divided then the quantity of Jouls per MegaPascal can be calculated (Figure 15b). This proportion enables to follow the relationship between the physical quantities. In this case, a non-linear tendency was evidenced, indicating the stress values do not have the same influence on the weld fracturing. Moreover, the values of energy can be easily connected with the values of stress (Table 8), covering more practical information for inspection groups. They can be used in comparison with the values of stress as well as 
total energy from the experiment and captured at operational conditions for predicting the lifetime of components made of the steel grade weld with similar mechanical parameters. The total energy to stress can be used at the current inspection without details on the earlier stage.

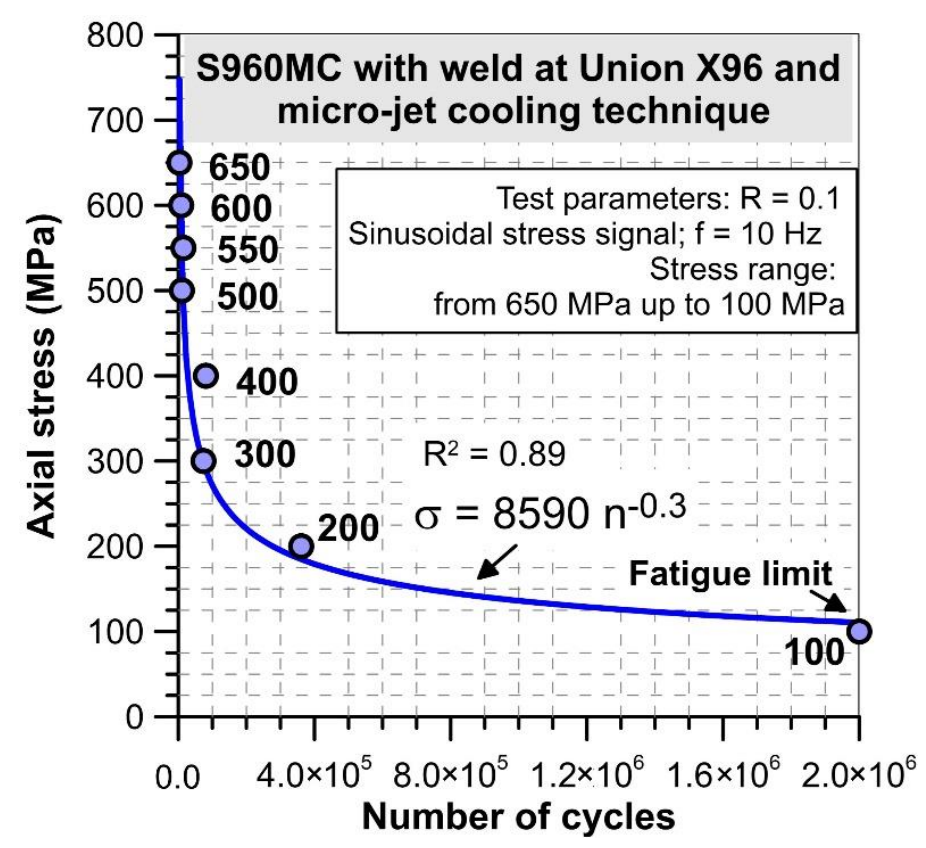

Figure 18. The Wöhler curve of S960MC steel welded by MAG method with the micro-jet cooling technique.

Table 8. Values of stress, total energy and their proportion.

\begin{tabular}{cccc}
\hline No. & $\begin{array}{c}\text { Maximum Value of } \\
\text { Stress (MPa) }\end{array}$ & Total Energy (J) & $\begin{array}{c}\text { Total Energy/Maximum } \\
\text { Value of Stress (J/MPa) }\end{array}$ \\
\hline 1. & 650 & 42 & 0.06 \\
2. & 600 & 57 & 0.10 \\
3. & 550 & 78 & 0.14 \\
4. & 500 & 38 & 0.08 \\
5. & 400 & 247 & 0.62 \\
6. & 300 & 141 & 0.47 \\
7. & 200 & 277 & 1.39 \\
8. & 100 & 449 & 4.49 \\
\hline
\end{tabular}

The role of the stress level in the weld degradation was determined on fracture zones represented by the general view on the specimens after the test (Figure 16) and exhibited by the view focused on the whole region of degradation (Figure 17). The photos were selected for presenting changes in the fracture regions and for better analysis of the zone degradation at various values of stress. Using them, we can follow the material degradation in a $3 \mathrm{D}$ coordinate system and compare it with the orientation of the measured zone. Some differences in the weld degradation due to cyclic loading are visible on the views on both parts of specimens directly after tests (Figure 16). They are expressed by the angular orientation of fracture zones at the stress level of 400-600 MPa, which indicates shear and axial components of stress for the weld decohesion. Comparing these data, a reduction of the angular orientation of the damage region is noticed, indicating the role of shear stress in the fracturing lowers with decreasing the stress value. This is better visible from the cross-section view (Figure 17).

The effect of the booth types of stress in the tested region degradation was also visible on the photos taken with the macro-photography technique (Figure 17). In this case, the 
same presentation concept for the following decohesion characteristics as was taken for the immediately fracture specimen was used. Using this approach, zone details in relation to fracture mechanics may be easier to collect. The multi-planar cracking was noticed on the perpendicular cross-sections as a major feature of all regions inspected independently of the stress level applied. Nevertheless, the proportion between the angular and horizontal sections of the damage zones was dependent on the values of stress, i.e., the horizontal part becomes more significant with decreasing the stress value (Figure 17g3).

The analysis of the fracture region represented by both zones, i.e., horizontal and angular, enables the selection of the area to be the first for damage occurrence. In this case, the horizontal section of the region considered plays the role of the initial damage. The second area that is damaged further and directly related to the final stage of specimen lifetime is represented by the angular region. This kind of data follows the micro-cooled welded region expresses a mixed (brittle-plastic) cracking at cyclic tensile stress arraigning the axial stress at the beginning of the fracture and shear stress at the final stage of fatigue. In comparison to the good plastic properties of the micro-cooled joint, these results reflect as follows: the weld degradation at plastic cracking is dominant under a stress value exceeding yield stress (530 MPa), while at a smaller one, the brittle behavior appeared.

An analysis of the Wöhler curve has enabled us to select stages with the number of cycles for applications or inspections of the weld tested at a wide range of stress values (Figure 18). For this case, the diagram can be divided at the following regions determined by the stress value and loading cycles: from $650 \mathrm{MPa}$ to $400 \mathrm{MPa}$ at $3 \times 10^{4}-9 \times 10^{4}$ cycles; from $400 \mathrm{MPa}$ to $100 \mathrm{MPa}$ at $9 \times 10^{4}-2 \times 10^{6}$ cycles. This enables to formulate as follows: the weld expresses hardening due to cyclic tensile stress close to the ultimate tensile strength reaching the lifetime limited by the $3 \times 10^{4}$. Moreover, the value of fatigue limit can be indicated as $100 \mathrm{MPa}$, which unfortunately does not express an attractive level for application under cyclic loading at very restricted operational regimes. This kind of result was very similar to data collected by the authors of [19]. Nevertheless, their data did not follow the function proposed as it was obtained in the paper. A comparison of these test results shows that they are complementary due to the different characteristics of the zones containing the welds and can be used for extending the knowledge in the S960MC weld behavior.

Concluding results from tests on the Wöhler curve worth noticing are that this kind of data can be analyzed not only at variations stress versus a number of cycles but also at changes of total energy. This approach collects the relationship between control and response signal, i.e., stress and strain, respectively, supporting results represented by one of the mentioned physical quantities. This kind of data can be used for modifying models for predicting lifetimes as well as elaborating on new ones. Fracture analysis is the stage of the fatigue test for analysis of fracture mechanics due to the type of loading applied. This follows the orientation of a fracture plane compared to a loading direction as well as details related to brittle or brittle-plastic cracking. The first mentioned feature of the region subjected to observation should be captured directly after a specimen fracturing without unmounting the tested object from the grips of the testing machine, while the second one's details are obtained from observations of a fracture plane from various directions. As it was evidenced in the photos of the fracture regions of the weld, the degradation mechanism was related to stress state components, i.e., the shear stress becomes more significant in the weld degradation with an increasing stress level becoming from a value close to the yielding point.

\section{Summary}

The article deals with MAG welding of thin-walled structures made of S960MC steel. It is a material used in automotive and offshore engineering [34]. Various welding parameters were tested, including micro-jet cooling parameters. To assess the quality of the joints, a series of non-destructive and destructive tests were performed. Welds were made with three different electrode wires and two different shielding gas mixtures. Main welding 
parameters and parameters of micro-jet cooling were varied. After the results of nondestructive tests, the main information was obtained on the proper welding parameters, where no cracks appeared. The results of non-destructive tests showed that the use of micro-jet cooling is very beneficial, as there were no welding cracks. The condition for a properly made joint was the correct selection of micro-jet cooling parameters. Then bending tests were performed. The results of these tests showed that in addition to cooling the micro-jet, the selection of the shielding gas is important. The use of the Ar gas mixture is beneficial, while the use of $\mathrm{CO}_{2}$ does not guarantee the possibility of obtaining joints with good plastic properties. Further research focused on the evaluation of joints made with three different welding wires. M21 cover and micro-jet cooling were always used. The U-notched specimen supports experiments for assessment of the quality of the welding process. Moreover, the specimen size was small, and all mechanical parameters of the static and fatigue behavior of the material and joints tested were determined. The results from the static and fatigue tests have extended the knowledge on the weld testing, the role of the three types of welding wires for the joint's quality manufactured by the micro-jet cooling technique, as well as applications and inspections. This was represented by variations of the stress-strain relationship, total energy directly at fracture and versus the number of cycles up to fatigue limit.

\section{Conclusions}

The results from the non-destructive and destructive experiments have enabled the following conclusions:

- The S960MC steel is very difficult for welding processes even when high technology is used, such as the micro-jet cooling method, and when different welding wires are applied because the weld's mechanical properties can be lowered by $50 \%$;

- The following welding parameters are recommended for MAG-welding sheet metal with a thickness of $2 \mathrm{~mm}: \mathrm{U}=19 \mathrm{~V}, \mathrm{I}=101 \mathrm{~A}, \mathrm{~V}=300 \mathrm{~mm} / \mathrm{min}$ and a mixture Ar- $18 \%$ $\mathrm{CO}_{2}$ as shielding gas;

- Elongation (10.50\%) of the weld produced at controlling micro-jet cooling with the three welding wires exceeded the value of this parameter (8.75\%) captured at the test of the base metal;

- At the same type of mechanical parameters, such as yield stress and ultimate tensile strength, their values were almost the same for all cases of the welds tested, i.e., $537 \mathrm{MPa}$ and $673 \mathrm{MPa}$, respectively. An increasing stress amplitude enabled following the differences in the behavior of the joints even they represent very similar response in static tests;

- The weld manufactured with the Union NiMoCr welding wire was the joint with the highest resistance on static and fatigue loadings. The response of the weld under cyclic loading should be analyzed not only in the general form represented by the Wöhler curve but also variations of total energy;

- As it was determined in the test, the value of energy at the fatigue limit reached $449 \mathrm{~J}$. In the case of the micro-jet cooled weld with the Union X96 welding wire, the difference between the value of stress from limited and unlimited sections was six times, following the value of fatigue limit of $100 \mathrm{MPa}$ at the final stage of the last-mentioned section;

- The use of micro-jet cooling when welding S960MC steel allows for obtaining joints with better mechanical properties (UTS $=700 \mathrm{MPa}, \mathrm{YS}=550 \mathrm{MPa}$ ).

Author Contributions: Data curation, A.J.; Formal analysis, B.S.-L., T.W. and B.Ł.; Funding acquisition, T.S., T.W. and B.Ł.; Investigation, T.S., B.S.-L. and A.J.; Methodology, T.S., B.S.-L., T.W. and A.J.; Supervision, B.S.-L., T.W. and B.E.; Validation, T.S.; Visualization, T.S. and B.S.-L.; Writing-original draft, T.S., B.S.-L. and T.W.; Writing-review \& editing, B.S.-L. and T.W. All authors have read and agreed to the published version of the manuscript.

Funding: This research was funded by Silesian University of Technology, grant number BK-277/RT1 2021. 
Institutional Review Board Statement: Not applicable.

Informed Consent Statement: Not applicable.

Data Availability Statement: Data sharing is not applicable to this article.

Acknowledgments: The paper is part of the COST project, CA 18223 and the research project No. 06/21/ZBH/012 in Motor Transport Institute, entitled "Examination of the mechanical resistance of materials and structural components in the conditions of laboratory strength simulation for applications in special vehicles".

Conflicts of Interest: The authors declare no conflict of interest.

\section{References}

1. Keeler, S.; Kimchi, M.; Mconey, P.J. Advanced High-Strength Steels Application Guidelines, Version 6.0; World Auto Steel: Brussels, Belgium, 2017; 314p.

2. Horvath, C.D. The Future Revolution in Automotive High Strength Steel Usage. In Proceedings of the Great Design in Steel Seminar, Livonia, MI, USA, 18 February 2004.

3. SSAB. Strenx 960MC; Data sheet 2015 Strenx 960MC 2017-04-20; SSAB: Borlänge, Sweden, 2017.

4. SSAB. Docol Press Hardening Steel, Technical Brochure; 345-en-Docol ${ }^{\circledR}$ Press hardening steel-v1-2020. Confetti; SSAB: Borlänge, Sweden, 2020.

5. Olsson, K.; Gladh, M.; Hedin, J.E.; Larsson, J. Microalloyed high-strength. Adv. Mater. Proces. 2006, 8, 44-46.

6. ArcelorMittal. Amstrong Ultra. The Smartest Choice; PR-BR-AMU-EN-10/2019; ArcelorMittal Europe Communications: Luxembourg, 2019.

7. Ruukki. Optim QC Structural Steels; Ruukki: Helsinki, Finland, 2014; 6p.

8. TATA Steel. High Strength Low Alloy; 20170314-FVC PVM; TATA Steel: Prague, Czech Republic, 2017.

9. Szymczak, T.; Brodecki, A.; Kowalewski, Z.L.; Makowska, K. Tow truck frame made of high strength steel under cyclic loading. Mater. Today Proc. 2019, 12, 207-212. [CrossRef]

10. SSAB. Strenx 960 for Stronger and Safer Rear Underrun Protection Device; 445-en-Strenx®960 for Stronger and Lighter RUPD V2-2019-A plus M-Österberg; SSAB: Österberg, Sweden, 2019; 2p.

11. Polish Committee of Standardization. PN-ISO 668:2018-05 Series 1 freight containers-Classification, dimensions and ratings; Polish Committee of Standardization: Warsaw, Poland, 2018.

12. Wiśnicki, B. Vademecum of Containerization. Forming the Container Load Unit; LINK: Szczecin, Poland, 2006.

13. Nordstroem, R.; Andersson, P.; Soekjer-Petersen, S. Verification of Level of Basic Parameters Important for the Dimensioning Of Cargo Securing Arrangements; Transport Research Institute: Stockholm, Sweden, 2004.

14. Szymczak, T.; Makowska, K.; Kowalewski, Z.L. Influence of the welding process on the mechanical characteristics and fracture of the S700MC high strength steel under various types of loading. Materials 2020, 13, 5249. [CrossRef] [PubMed]

15. Wegrzyn, T.; Szymczak, T.; Szczucka-Lasota, B.; Łazarz, B. MAG Welding process with micro-jet cooling as the effective method for manufacturing joints for S700MC steel. Metals 2021, 11, 276. [CrossRef]

16. Szczucka-Lasota, B.; Węgrzyn, T.; Szymczak, T.; Jurek, A. High martensitic steel after welding with micro-jet cooling in microstructural and mechanical investigations. Materials 2021, 14, 936. [CrossRef]

17. Jambor, M.; Novy, F.; Mician, M.; Trsko, L.; Bokuvka, O.; Pastorek, F.; Harmaniak, D. Gas metal arc welding of thermomechanically controlled processed S960MC steel thin sheets with different welding parameters. Communication 2018, 4, 29-34. [CrossRef]

18. Siltanen, J.; Tihinen, S.; Kömi, J. Laser and laser gas-metal-arc hybrid welding of $960 \mathrm{MPa}$ direct-quenched structural steel in a butt joint configuration. J. Laser Appl. 2015, 27, S29007. [CrossRef]

19. Bhatti, A.; Barsoum, Z.; Mee, V.V.D.; Kromm, A.; Kannengiesser, T. Fatigue strength improvement of welded structures using new low transformation temperature filler materials. Procedia Eng. 2013, 66, 192-201. [CrossRef]

20. Mičian, M.; Maronek, M.; Konar, R.; Harmaniak, D.; Jambor, M.; Trško, L.; Wincek, J. Changes of microstructure and mechanical properties of the HAZ of the S960MC steel sheet weld joint. Zavar. Zavarene Konstr. 2020, 3, 113-123. [CrossRef]

21. Jambor, M.; Ulewicz, R.; Nový, F.; Bokůvka, O.; Trško, L.; Mičian, M.; Harmaniak, D. Evolution of microstructure in the heat affected zone of S960MC GMAW weld. In Proceedings of the 10th Conference on Terotechnology, Kielce, Poland, 18-19 October 2017; pp. 78-83. [CrossRef]

22. Schneider, C.; Ernst, W.; Schnitzer, R.; Staufer, H.; Vallant, R.; Enzinger, N. Influence of different welding processes on the mechanical properties of structural steel S960MC. Thermec Graz 2016. Available online: https:/ /pure.tugraz.at/ws/portalfiles/ portal/3629530/poster.pdf (accessed on 19 May 2021).

23. Steimbreger, C.; Gubeljak, N.; Enzinger, N.; Ernst, W.; Chapetti, M. Influence of static strength on the fatigue resistance of welds. MATEC Web Conf. 2018, 165, 13010. [CrossRef]

24. Górka, J.; Kotarska, A. MAG welding of 960QL quenched and tempered steel. IOP Conf. Ser. Mater. Sci. Eng. 2019, 591, 1-8. [CrossRef] 
25. Tomków, J.; Fydrych, D.; Wilk, K. Effect of electrode waterproof coating on quality of underwater wet welded joints. Materials 2020, 13, 2947. [CrossRef] [PubMed]

26. Fydrych, D.; Łabanowski, J.; Tomków, J.; Rogalski, G. Cold cracking of underwater wet welded S355G10+N high strength steel. Adv. Mater. Sci. 2015, 15, 48-56. [CrossRef]

27. Wang, X.; Wu, J.-F.; Qian, X. Crack driving force and ultimate strength of thick-walled CHS X-joints with near-toe cracks, paper number: ISOPE-I-11-203. In Proceedings of the Twenty-first International Offshore and Polar Engineering Conference, Maui, HI, USA, 19-24 June 2011.

28. Węgrzyn, T.; Szczucka-Lasota, B.; Uściłowska, A.; Stanik, Z.; Piwnik, J. Validation of parameters selection of welding with micro-jet cooling by using method of fundamental solutions. Eng. Anal. Bound. Elements 2019, 98, 17-26. [CrossRef]

29. Wegrzyn, T. The Classification of Metal Weld Deposits in Terms of the Amount of Oxygen. In Proceedings of the Conference of International Society of Offshore and Polar Engineers ISOPE'99, Brest, France, 30 May-4 June 1999; International Society of Offshore and Polar Engineers: Cupertino, CA, USA, 1999; Volume IV, pp. 212-216. ISBN 1-880653-43-5.

30. Górka, J. Assessment of the weldability of T-welded joints in $10 \mathrm{~mm}$ thick TMCP steel using laser beam. Materials 2018, 11, 1192. [CrossRef] [PubMed]

31. ISO. Welding_Fusion-Welded Joints in Steel, Nickel, Titanium and their Alloys (Beam Welding Excluded)—Quality Levels for Imperfections; PN-EN ISO 5817:2014; ISO: Warsaw, Poland, 2014.

32. Hadryś, D. Impact load of welds after micro-jet cooling/dynamiczne obciążenie spoin chłodzonych mikrojetowo. Arch. Met. Mater. 2015, 60, 2525-2528. [CrossRef]

33. WaveMatrixTM. Software-V1.4 Onwards; Software Reference Manual M22-16102-EN Revision B; Instron: High Wycombe, UK, 2009; 368p.

34. Aderinola, O.O.; Kah, P.; Martikainen, J. Efficient welding technologies applicable to HSS arctic offshore structures. In Proceedings of the Twenty-third International Offshore and Polar Engineering Conference, Paper Number: ISOPE-I-13-639, Anchorage, AL, USA, 30 June-5 July 2013. 